\title{
Development and Evaluation of Curcumin Encapsulated Self-assembled Nanoparticles as Potential Remedial Treatment for PCOS in a Female Rat Model
}

\author{
Mazhar Ali Raja ${ }^{1,2}$ \\ Martin Maldonado ${ }^{2}$ \\ Jianying Chen ${ }^{2}$ \\ Ying Zhong ${ }^{2}$ \\ Jiang $\mathrm{Gu}^{1,2}$
}

'Laboratory of Molecular Pathology, Provincial Key Laboratory of Infectious Diseases and Molecular Pathology, Center of Molecular Diagnosis and Personalized Medicine, Shantou University Medical College, Shantou, People's Republic of China; ${ }^{2}$ Chengdu Jinxin Research Institute for Reproductive Medicine and Genetics, Reproductive Center of Chengdu Jinjiang District Maternal and Child Health Hospital, Chengdu, People's Republic of China

Correspondence: Jiang Gu Laboratory of Molecular Pathology, Provincial Key Laboratory of Infectious Diseases and Molecular Pathology, Center of Molecular Diagnosis and Personalized Medicine, Shantou University Medical College, Xinling Road 22, Shantou, Guangdong, 51504I, People's Republic of China

Email 2523381625@qq.com; jgu@stu. edu.cn

Ying Zhong

Chengdu Jinxin Research Institute for ReproductiveMedicine and Genetics, ReproductiveCenter of Chengdu Jinjiang District Maternal and Child Health Hospital, No. 66, 88 Bi Sheng Road, Chengdu, 610023, People's Republic of China

Email zhongy@jxr-fertility.com
Purpose: Polycystic ovary syndrome (PCOS) is one of the most common endocrinopathies affecting women of reproductive age and leads to metabolic disorders and infertility. The present study was conducted to investigate the therapeutic effects of curcumin (Cur) encapsulated arginine (Arg) and $\mathrm{N}$-acetyl histidine (NAcHis) modified chitosan (Arg-CS-NAcHis /Cur) nanoparticles (NPs).

Methods: In this study, amphiphilic chitosan (CS) conjugate was developed by modification with hydrophilic arginine (Arg) and hydrophobic N-acetyl histidine (NAcHis) group (ArgCS-NAcHis). The synthesized conjugate was well characterized by FTIR and NMR studies. Self-assembled nanoparticles based on the synthesized conjugate were developed by simple sonication method and characterized for the physicochemical properties of zeta potential, particle size and drug encapsulation. Next, in vitro drug release, cytotoxicity, and cellular uptake studies of the NPs were evaluated. Finally, the developed nanoparticles were examined for their therapeutic potential against estradiol valerate (EV) induced PCOS rats by evaluating hormone level changes and ovarian morphology.

Results: The results showed that zeta potential of the nanoparticles was $39.8 \pm 2.52 \mathrm{mV}$ and the average size was $200 \mathrm{~nm}$. The in vitro drug release profile showed sustained release pattern. Cytotoxicity and cellular uptake studies also showed preferential effectiveness than free curcumin. Both the biochemical and histopathological studies showed positive effects in reverting the symptoms of PCOS rats to normalcy.

Conclusion: Curcumin encapsulated arginine and $\mathrm{N}$-acetyl histidine modified chitosan (Arg-CS-NAcHis/Cur) nanoparticles have been successfully developed. The present study suggested that treatment of the nanoparticles might reverse many of the PCOS symptoms. Therefore, these nanoparticles might be used as promising new candidate for delivery of curcumin to treat PCOS.

Keywords: polycystic ovary syndrome, curcumin, self-assembled nanoparticles, cytotoxicity, cellular uptake

\section{Introduction}

Polycystic ovary syndrome (PCOS) is one of the most complex and common endocrinopathies affecting around $15 \%$ of the female population of reproductive age and increases the lifelong risks of endocrine, metabolic and reproductive functions. $^{1,2}$ It is mainly manifested by ovarian dysfunction, hyperandrogenism, metabolic disorders, polycystic ovarian morphology, dyslipidemia, and insulin 
resistance. ${ }^{3}$ Earlier research has suggested that resistance of insulin due to decreased ability of body cells to respond against insulin signaling is an important pathophysiological mechanism for the progression of all metabolic complications in PCOS. ${ }^{4}$ The higher insulin concentration in blood plasma is also associated with decreased level of sex-hormone binding globulin (SHGB) resulting in increased bioavailability of androgen hormones. Overall, in connection with PCOS, hyperandrogenemia and insulin resistance continuously act together and thus potentiate each other's effects in a reciprocal way for the progressive development of both reproductive as well as metabolic complications. ${ }^{5-8}$ Besides, PCOS increases the threat of cardiovascular diseases and endometrial cancer. ${ }^{9}$ Moreover, pregnant women with PCOS are prone to type-2 diabetes mellitus, miscarriage, and infertility. ${ }^{10,11}$ Although first reported as early as 1953 , the clinical treatment and etiology of PCOS still need to be explored.

The application of nanotechnologies in the biomedical field for diagnostic purposes and controlled drug delivery of different drugs is termed as nanomedicine. ${ }^{12,13}$ The tremendous growth of nanomedicines over the last three decades has burst into inspiring novelties in the field of pharmacology and has revolutionized the delivery of pharmaceutically active compounds. This progress has successfully developed many nano-therapeutics for a variety of human ailments. ${ }^{14}$ In this regard, synthesis of nanoparticles using biocompatible polymers like chitosan (CS) draws researchers attention due to their properties such as easy manipulation and rapid solubility. ${ }^{15,16}$ Despite the fact that chitosan possesses impressive biomedical benefits, its poor aqueous solubility at body's $\mathrm{pH}$ hinders its application as effective biopolymer, and this drawback can be overcome by modification with chemical moieties. ${ }^{17-19}$ After chitosan functionalization and structural manipulation, different drug molecules can be encapsulated. This encapsulation of active pharmaceutical drug within the chitosan polymer allows for a greater control of the active drug pharmacokinetic behavior. ${ }^{20}$

Amino acids are chiral molecules and building blocks of our body's proteins with low molecular weight and different properties depending on the side chain attached. The grafting of chitosan's backbone with amino acids not only improves the physicochemical behavior of chitosan, but also results in interesting synergistic characteristics for applications in drug delivery. ${ }^{21}$ In addition, previous research has proved that administration of different amino acids like arginine and cysteine improve gonadal functions in PCOS patients and also increase insulin sensitivity. ${ }^{22}$ Histidine also finally converts into histamine and plays its role in immunity and sexual function. ${ }^{23,24}$

Recently, drugs extracted from plant origin have increased because herbal therapies not only possess fever side effects, but also have potential rehabilitative, curative, and preventive capacity. ${ }^{25,26}$ Moreover, Arentz et $\mathrm{al}^{27}$ in their published study, revealed that women with PCOS expressed strong dissatisfaction toward pharmaceutical therapies and the prevalence of use for complementary medicines was over $70 \%$ that advocate strong preferences of women for complementary treatments. Moreover, conventional pharmaceutical management is limited by the prevalence of contraindications in women with PCOS, non-effectiveness in some circumstances and side effects. ${ }^{28-30}$ In todays medical world, different herbal drugs are being utilized for PCOS treatment. Maharjan et $\mathrm{al}^{31}$ showed that Aloe barbadensis gel treatment had positive recovery effects on a PCOSinduced animal model. In another study, flower extract of Matricaria chamomilla enhanced the normal follicle development in PCOS rats. ${ }^{32}$ Merrily and Winston reported that plant Gymnema sylvestre has trophorestorative action on the beta cells of the pancreas and is well indicated for PCOS, due to its insulin modulating activity and the property of reducing the elevated triglycerides associated with the disorder. ${ }^{33}$

Curcumin (Cur) is a hydrophobic yellow compound extracted from Curcuma longa and has been used as food additive and natural remedy in India and the People's Republic of China since ancient times as it possesses diverse pharmacological and biological activities. ${ }^{34-}$ ${ }^{39}$ Chronic inflammation is considered an important contributor to the pathogenesis of PCOS, which is also reflected by altered levels of inflammatory markers. ${ }^{40-43}$ In a study published by Shima et $\mathrm{al}^{44}$ curcumin was evaluated for its total effects on PCOS patients and reported that insulin resistance and inflammation can be reduced with different concentrations of curcumin. Earlier research has reported "hyperandrogenism" as the main hallmark of PCOS due to increase of androgen production by the ovaries. ${ }^{45,46}$ Moreover, the anti-androgenic effects of curcumin are also well established in previous literature. $^{47}$

The major goal of this research was to study the fabrication of self-assembled nanoparticles based on arginine (Arg) and $\mathrm{N}$-acetyl Histidine (NAcHis) modified chitosan conjugate (Arg-CS- NAcHis). We hypothesized 
that (Arg-CS-NAcHis) conjugate could self-assemble to form NPs when dissolved in water and the hydrophobic Cur could be entrapped within the NPs that might lead to stabilize Cur in aqueous media. Moreover, the chemical moieties in fabrication of nanoparticles would aid in each other's therapeutic effects to achieve a better natural drug delivery system against PCOS. Cur-loaded (Arg-CSNAcHis) modified chitosan NPs (Arg-CS-NAcHis)/Cur NPs) were developed by the simple method of sonication and evaluated for their potential as a drug delivery system for the treatment of PCOS. Meanwhile, the physicochemical characteristics of curcumin-loaded NPs (eg, size, surface morphology, and encapsulation efficiency) were investigated. An in vitro release study was carried out to study the release behavior of Cur. Furthermore, the cytotoxicity and cellular uptake in KGN cells (a human granular carcinoma cell line) were studied. Finally, the gonadotrophic hormone levels and histopathological changes were determined in estradiol valerate (EV) induced PCOS model to evaluate the potential of nanoparticle treatment against PCOS.

\section{Materials and Methods Materials}

Ultrapure chitosan having low molecular weight $\left(\mathrm{M}_{\mathrm{n}}=50\right.$ $\mathrm{kDa}$, deacetylation degree of 91\%) was purchased from Laizhou Haili Biological Products Co. Ltd (Shandong, China). N-hydroxysuccinimide (NHS), L-arginine and ethyl-3-(3-dimethylaminopropyl) carbodiimide hydrochloride (EDC) were purchased from Sigma Chemicals Company (St Louis, MO, USA). N-acetyl histidine (NAcHis) was purchased from Tokyo Chemical Industry Co. Ltd (Tokyo Japan). Curcumin (95\% total curcuminoids) was purchased from Aladdin Chemistry Co. Ltd (Shanghai, China). Purified pyrene was supplied by Sigma Chemicals Company (St Louis, MO, USA). The cell culture medium, streptomycin, fetal bovine serum and penicillin were procured from Hyclone Company (USA). All other reagents used were of analytical grade or purer and water was double distilled.

\section{Cell Culture}

KGN cells (a human granular carcinoma cell line) as approved for experimental use by the Institutional Ethical Review Committee of Chengdu Xinan Gynecological Hospital, Chengdu, Sichuan, China (sister organization of Jinjiang Hospital for Maternal and Child Health Care, Chengdu, China) was received as gift sample from
Department of Clinical Laboratory, Chengdu Xinan Gynecological Hospital, Chengdu China. The KGN cells were maintained in DMEM/F12 supplemented with $10 \%$ FBS, $100 \mathrm{U} / \mathrm{mL}$ penicillin and $100 \mu \mathrm{g} / \mathrm{mL}$ streptomycin in a humidified atmosphere of $5 \% \mathrm{CO}_{2}$ at $37^{\circ} \mathrm{C}$. The growth medium was changed every two-to-three days.

\section{Synthesis of Arginine and $\mathrm{N}$-acetyl Histidine-modified Chitosan Conjugates}

The arginine (Arg) and N-acetyl histidine (NAcHis)modified chitosan conjugate were synthesized in two steps with the help of EDC/NHS as coupling agents by the reaction of carboxylic group of amino acid with primary amine groups of chitosan as previously described by Liu et $\mathrm{al}^{48}$ with minor modifications. First, at $25^{\circ} \mathrm{C}$ chitosan was dissolved in $10 \mathrm{mM}$ TEMED/HCL having $\mathrm{pH} 6.0$ to a $1 \% \mathrm{v} / \mathrm{v}$ concentration. The EDC and NHS in a particular ratio was dispersed in the same buffer solution with constant stirring for activation carboxylic group of chitosan. Then, L-arginine was mixed up and the reaction was kept continued for $24 \mathrm{~h}$. The unreacted components from the chitosan-arginine polymer were removed by dialyzing against distilled water for three days. Finally, functionalization with different amounts of $\mathrm{N}$-acetyl histidine $(0.24,0.48$, and $0.72 \mathrm{mg})$ was carried out separately to yield conjugates with different substitution degree and stored at room temperature. Colloidal titration method was used to evaluate the substitution degree of $\mathrm{N}$-acetyl histidine and arginine on chitosan backbone as previously described. ${ }^{49}$

\section{Synthesis of Self-assembled Nanoparticles Based on Amphiphilic Chitosan Conjugate} The $20 \mathrm{mg}$ of prepared amphiphilic chitosan conjugate was dissolved with constant stirring at $25^{\circ} \mathrm{C}$ for $24 \mathrm{~h}$ and then sonicated with probe-type sonifier (Sonics Ultrasonic Processor, VC750) in ice bath at $90 \mathrm{~W}$ for six minutes each, repeated for at least three times. The resultant nanoparticulate solution was then filtered through a filter of $0.8 \mu \mathrm{m}$ pore size to remove dust and other unreacted components.

\section{Preparation of Curcumin Encapsulated Arginine and $\mathrm{N}$-acetyl Histidine-modified Chitosan Nanoparticles and \\ Encapsulation Efficiencies}

Curcumin encapsulated arginine and $\mathrm{N}$-acetyl histidine modified chitosan (Arg-CS- NAcHis/Cur) nanoparticles 
in this study were prepared by dialysis method. ${ }^{50}$ In short, overnight alkalinization of curcumin was carried out in DMSO, solution of curcumin in DMSO was then mixed up with aqueous solution of modified chitosan nanoparticles under constant stirring. Then, the obtained mixture was dialyzed for $24 \mathrm{~h}$ at $4^{\circ} \mathrm{C}$ against distilled water using a dialysis membrane (MWCO $12 \mathrm{kDa}$ ). For removal of insoluble free curcumin and other impurities the resultant solution was then centrifuged at $3000 \mathrm{rpm}$ for $10 \mathrm{~min}$ and filtered through a $0.8 \mu \mathrm{m}$ membrane. Soluble and free curcumin from the nanoparticles was separated through filtration using a membrane filter (MWCO $10 \mathrm{kDa}$ ). In order to measure the amount of drug loading and encapsulation, curcumin encapsulated self-assembled nanoparticles were dispersed in aqueous solution of DMSO and the absorbance at $490 \mathrm{~nm}$ was measured through UV-vis spectrophotometer. The encapsulation and loading efficiencies were calculated using equation 1 and equation 2 respectively as follows: ${ }^{51}$

$$
\begin{aligned}
& \mathrm{EE}=\frac{\text { Weight of drug in nanoparticles }}{\text { Weight of the initial drug }} \times 100 \% \\
& \mathrm{LE}=\frac{\text { Weight of drug in nanoparticles }}{\text { Weight of nanoparticles }} \times 100 \%
\end{aligned}
$$

\section{Characterizations of Modified Chitosan}

\section{Conjugate and Nanoparticles}

Fourier Transform Infrared (FTIR) Spectroscopy and 'H Nuclear Magnetic Resonance ('HNMR)

\section{Spectroscopy}

The FTIR and NMR analyses were carried out to demonstrate the grafting of amino acids on chitosan backbone. The FTIR spectra of bare chitosan and modified chitosan polymer were recorded by Shimadzu 8300 FTIR Spectrophotometer over the range $400-4000 \mathrm{~cm}^{-1}$ with resolution of $4 \mathrm{~cm}^{-1}$ and 64 scan acquisition following the method as described previously by Shigemasa et al. ${ }^{52}$ The dried sample ( $2 \mathrm{mg}$ ) was mixed with $\mathrm{KBR}$ powder and pressed into a pellets at $20^{\circ} \mathrm{C}$ for spectra analysis.

In addition, to further verify the conjugation of amino acids onto chitosan backbone ${ }^{1} \mathrm{HNMR}$ spectra of bare chitosan and Arg-CS-NAcHis was recorded by using a ${ }^{1} \mathrm{H}$ Nuclear Magnetic Resonance Spectrometer (Bruker AV $600 \mathrm{MHz}$, Germany). Approximately, $5 \mathrm{mg}$ samples solution in DMSO was prepared in $5 \mathrm{~mm}{ }^{1} \mathrm{HNMR}$ tube and mixed ultrasonically to dissolve at a final concentration of $5 \mathrm{mg} / \mathrm{mL}$. The ${ }^{1} \mathrm{HNMR}$ spectra was obtained with the following conditions; number of data points $298 \mathrm{~K}$, relaxation delay between scans 1 second; acquisition time 3.75 second with number of scan 80 .

\section{Self-aggregation or Self-assembled Behavior}

To evaluate the self-assembling or self-aggregation pattern of the synthesized nanoparticles, the CAC value of the nanoparticles was estimated by standard pyrene method using Shimadzu, RF-5301PC fluorescence spectrophotometer). ${ }^{53-55}$ Briefly, tubes containing $1 \mathrm{mg}$ crystal of pyrene were prepared. Then, polymer solution of different concentration $\left(10^{-4} \mathrm{M}\right.$ to $\left.10^{-6} \mathrm{M}\right)$ was added to make the final concentration of pyrene as $6.0 \times 10^{-7} \mathrm{mg} / \mathrm{mL}$. The mixture was then equilibrated at room temperature for $24 \mathrm{~h}$. Finally, the pyrene emission spectra was obtained in the range of $300-450 \mathrm{~nm}$ at an excitation wavelength of $330 \mathrm{~nm}$ and emission wavelength of $390 \mathrm{~nm}$. To measure the value of $\mathrm{CAC}$, fluorescence intensity ratio of the first and third peak was calculated and drawn against the logarithmic polymer concentration.

\section{Measurements of Zeta Potential and Polydispersity Index}

Nanoparticle aqueous solution $(1 \mathrm{mg} / \mathrm{mL})$ was analyzed at $25^{\circ} \mathrm{C}$ for dynamic light scattering (DLS) and zeta potential measurement using Malvern nano-ZS Zetasizer (Malvern, UK). Polydispersity index and distribution profile of the sample was calculated with the software provided by Malvern. The zeta potential of the nanoparticles was measured using laser Doppler velocimetry (LDV) techniques. All measurements were performed three times at wavelength $635 \mathrm{~nm}$ with a fixed scattering angle of $90^{\circ}$.

\section{Morphology Observation by TEM}

The morphology of the nanoparticle solution $(1 \mathrm{mg} / \mathrm{mL})$ was observed with transmission electron microscopy using negative staining with $1.0 \%$ phosphotungstic acid. A drop of the sample was placed on the surface of copper grid. Then the sample was stained with $1.0 \%$ phosphotungstic acid and dried in open air. The appearance was examined under an EM 400 transmission electron microscope (TEM) (Philips, Netherlands) operating at an accelerating voltage of $80 \mathrm{kV}$.

\section{In vitro Drug Release Study}

In vitro release studies of curcumin from synthesized nanoparticles was evaluated by dialysis method using a pH changing system (acetate: $\mathrm{pH} 4.0$ and 5.0; phosphate: $\mathrm{pH}$ 6.0, 6.8, and 7.4) following the recommendations on dosage form testing described in European Pharmacopeia 
7.0. Briefly, $3 \mathrm{~mL}$ of NPs solution was sealed into a dialysis bag (MWCO $12 \mathrm{kDa}$ ) and dialyzed extensively under mechanical shaking at $100 \mathrm{rpm}$ and $37^{\circ} \mathrm{C}$. At prefixed time intervals, $2 \mathrm{~mL}$ of the sample was withdrawn and replenished with fresh medium. The released drug content was quantified by UV- visible spectrophotometer at $488 \mathrm{~nm}$ in comparison with calibration curve.

\section{The Cytotoxicity Assay}

The cytotoxicity assay was evaluated in KGN cells (a human granular carcinoma cell line) preserved in RPMI 1640 medium supplemented with $1 \%$ penicillin and streptomycin, $10 \%$ fetal bovine serum and maintained in a fully humidified atmosphere at $37^{\circ} \mathrm{C}$ with $5 \% \mathrm{CO}_{2}$. The cells were seeded in a 96-well plate at $5 \times 10^{3}$ cells/well and allowed to grow for $24 \mathrm{~h}$. Then the culture medium was replaced with free curcumin, blank and curcumin-loaded nanoparticle solutions and further incubated for 24, 48, and $72 \mathrm{~h}$ respectively. Finally, the cell viability was measured with MTT method at absorbance value of $492 \mathrm{~nm}$.

\section{Intracellular Uptake Study}

When curcumin is viewed under a $535-600 \mathrm{~mm}$ filter, it emits green fluorescence. Hence intracellular uptake of curcumin and curcumin-loaded self-assembled nanoparticles was determined using a fluorescence microscope (Olympus IX51, USA) attached to an Olympus camera (DP70 Digital, USA). The KGN cells (a human granular carcinoma cell line) were harvested on cover slips carefully placed in six-well plates at $\left(5 \times 10^{5}\right.$ cells/well $)$ and incubated for $24 \mathrm{~h}$ at $37^{\circ} \mathrm{C}$. The cells were then exposed to fresh medium containing free curcumin or NPs with equivalent concentration of curcumin $(5 \mu \mathrm{g} / \mathrm{mL})$ and incubated for 1 and $4 \mathrm{~h}$. Later, cells were washed at least three times with cold PBS and fixed with 3\% paraformaldehyde solution. Then, the cover slips were viewed under confocal laser scanning microscope (CLSM, Leica, Germany) for intracellular curcumin fluorescence.

\section{In vivo Study on PCOS Animal Model Animal}

All experimental protocols were performed in accordance with National Institution of Health guidelines for the care and use of laboratory animals and the study was approved by Ethical Review Committee of Chengdu Xinan Gynecological Hospital, Chengdu, Sichuan, China (sister organization of Jinjiang Hospital for Maternal and Child
Health Care, Chengdu, China); and every effort was made to minimize both the number of animals and their suffering. Forty healthy female Wistar rats with weights ranging between 90 and $120 \mathrm{~g}$ were purchased from Chengdu Dossy Experimental Animals Co., Ltd (license no. SCXK (Sichuan) 2013-24, China) and used for this study. All animals were kept in standard environmental conditions $\left(20^{\circ} \mathrm{C}, 12 \mathrm{~h}\right.$ light $)$ with free access to rodent feed and water according to the standard guidelines.

\section{Induction of PCOS Rat Models and Animal Treatment}

PCOS rat models were produced according to the method already established by Lai et $\mathrm{al}^{56}$ and Brawer et $\mathrm{al}^{57}$ with little modification. All rats chosen for the study were displaying at least two consecutive normal four-day estrous cycles and were at the same estrous stage determined by vaginal smear for each rat. They were acclimatized to the laboratory environment for a week prior to the commencement of the experiments. The animals were then weighed and randomly divided into four experimental groups and one control group ( $\mathrm{n}=8$ in each group). A single dose of EV $(2 \mathrm{mg} / \mathrm{kg})$ body weight in $0.2 \mathrm{~mL}$ corn oil $(\mathrm{v} / \mathrm{v})$ was injected intraperitoneally to the animals in experimental groups. The successful formation of polycystic ovaries in experimental groups were confirmed according to the published criteria. ${ }^{58}$ The control group rats received equivalent amounts of vehicle only $(0.2 \mathrm{~mL}$ corn oil). The PCOS group treated with metformin $(50 \mathrm{mg} /$ $\mathrm{kg}$ body weight), the PCOS group administered with free curcumin $(50 \mathrm{mg} / \mathrm{kg}$ body weight) and the PCOS group administered with synthesized nanoparticle solution (50 mg/kg body weight). The treatment was once daily with per oral administration of the respective dosage as outlined above and lasted for 21 days. During the entire period of treatment, the animals were weighed every four days and vaginal smear was taken daily beginning 10 days after first injection until the end of experiment.

\section{Estrous Cycle}

The estrous cycle of each female rat in all groups were determined with vaginal smear method as previously described elsewhere. ${ }^{59}$ Briefly, vaginal smear was collected every morning with a cotton bud filled with normal saline $(\mathrm{NaCl} 0.9 \%)$. The sample were then spread on a clean slide and dried. After fixing in methanol the cells were stained with Giemsa. The stained slides were drained, washed, air dried and examined with a light 
microscope (Olympus, Tokyo, Japan) at $100 \times$ and $400 \times$ magnification.

Persistent vaginal cornification was defined and considered as an indication of follicle cyst development during a minimum time period of 10 days by finding and observing cornified cells in the collected smears. ${ }^{60}$

\section{Hormonal Measurement}

The effects of the synthesized nanoparticles, free curcumin and standard drug metformin on hormonal levels were evaluated by ELISA. Briefly, the effects were determined in PCOS-induced rats on the twenty-first day of treatment period after sacrificing the animals by decapitation. Blood samples from the groups were collected by retro orbital puncture using light ether as an anesthetic agent. Serum was separated at $3500 \times \mathrm{g}$ for $10 \mathrm{~min}$ at room temperature. The concentration of serum follicle stimulating hormone (FSH); luteinizing hormone (LH); testosterone (T); prolactin (PRO); progesterone (PRG) and insulin (INS) levels were estimated by ELISA Kits (Elabscience Biotechnology Co., Ltd, Wuhan, China) with reference numbers; E0830r, E1174r, E0458Ge, E0846r, E0459Ge, and E0448r respectively. In brief, $50 \mu \mathrm{L}$ each of the standards, control and serum samples were added to respective wells coated with hormonal antibody and incubated with $50 \mu \mathrm{L}$ of enzyme conjugate for two hours at $37^{\circ} \mathrm{C}$ in an oven (Echo Therm, USA). Subsequently, the wells were rinsed three times with distilled water and $50 \mu \mathrm{L}$ of the substrate was added and incubated for 15 $\min$ at $37^{\circ} \mathrm{C}$. Reactions were terminated using $50 \mu \mathrm{L}$ of stop solution. The optical density (OD) was measured at $450 \mathrm{~nm}$ using a microplate reader (BioTek, USA). For determination of each hormonal level, a standard curve was constructed by plotting a graph of the absorbance of each reference standard against its corresponding levels. The inter-assay and intra-assay variations were found to be less than $15 \%$. Each sample was run in duplicate and all the procedures were carried out according to standard manufacturer's protocol.

\section{Ovarian Morphology}

Rats were anesthetized with sodium pentobarbital (Nembutal ${ }^{\circledR}$ ) 50-90 mg/kg IP, weighed and sacrificed. The ovarian tissues were dissected from the rats, cleaned of adherent connective fat tissues and immediately fixed in $10 \%$ formaldehyde (v/v) solution for at least $24 \mathrm{~h}$. Then dehydrated in ascending grades of ethanol, cleaned in xylene and embedded in paraffin. Sections were cut in 5 $\mu \mathrm{m}$ thickness and then stained with hematoxylin and eosin (H\&E) for the histopathological studies. The same pathologist who had no knowledge of the experimental data, reviewed histologic slides.

\section{Statistical Analysis}

All statistical analyses were performed with software Prism (GraphPad Prism 6.01). ChemDraw 7.0 was used to process the chemical structure. Hormonal assay were analyzed using one-way analysis of variance (ANOVA) followed by Bonferroni test for multiple comparisons to identify significant difference between groups. All experiments were conducted at least three times on separate occasions. All data were expressed as the mean \pm standard error for each group. A value of $p<0.05$ was considered significant in all the analyses.

\section{Results and Discussion Synthesis and Characterization}

A two-step modification method was employed to synthesize the polymeric conjugate "arginine and $\mathrm{N}$-acetyl histidine modified chitosan (Arg-CS- NAcHis)" using coupling reagents EDC and NHS. Figure 1 shows the synthetic pathway of the modified conjugate. FTIR and ${ }^{1}$ HNMR analysis were used to confirm the synthesis of amphiphilic conjugate. The FTIR spectra of chitosan and modified chitosan is represented in Figure 2; the peak for the native chitosan at $1556.35 \mathrm{~cm}^{-1}$ indicated (amide bond formation) the glucosamine monomer of chitosan (N-H bending). After successful grafting with arginine and $\mathrm{N}$-acetyl histidine, an increase in the amide bond $\left(\approx 1605.60 \mathrm{~cm}^{-1}\right)$ and $\left(\approx 1648.33 \mathrm{~cm}^{-1}\right)$ was observed in spectral analysis revealing the formation of extra amide bond during the coupling reaction. This confirm the conjugation of arginine and $\mathrm{N}$-acetyl histidine onto the chitosan polymeric chain.

The grafting of amino acids onto chitosan chain was further confirmed by ${ }^{1}$ HNMR spectroscopic analysis. The ${ }^{1}$ HNMR spectra of both modified conjugate and unmodified chitosan is represented in Figure 3. The additional peak present at $\delta \approx 1.7 \mathrm{ppm}$ (A) could be attributed to the presence of $\left(-\mathrm{CH}_{2}-\right)$ group in acetyl histidine and arginine. The presence of peaks at $\delta \approx 3.6 \mathrm{ppm}$ (B) could be assigned to the $-\mathrm{CH}_{2} \mathrm{NH}$ in arginine. The emergence of peaks at $\delta \approx 6.8 \mathrm{ppm}(\mathrm{F})$ were due to the anomeric carbon signaling of chitosan. The appearance of peak at $\delta \approx 3.2 \mathrm{ppm}$ (E) was due to $\mathrm{CH}_{3}$ group of chitosan. Furthermore, the presence of characteristic peak at 

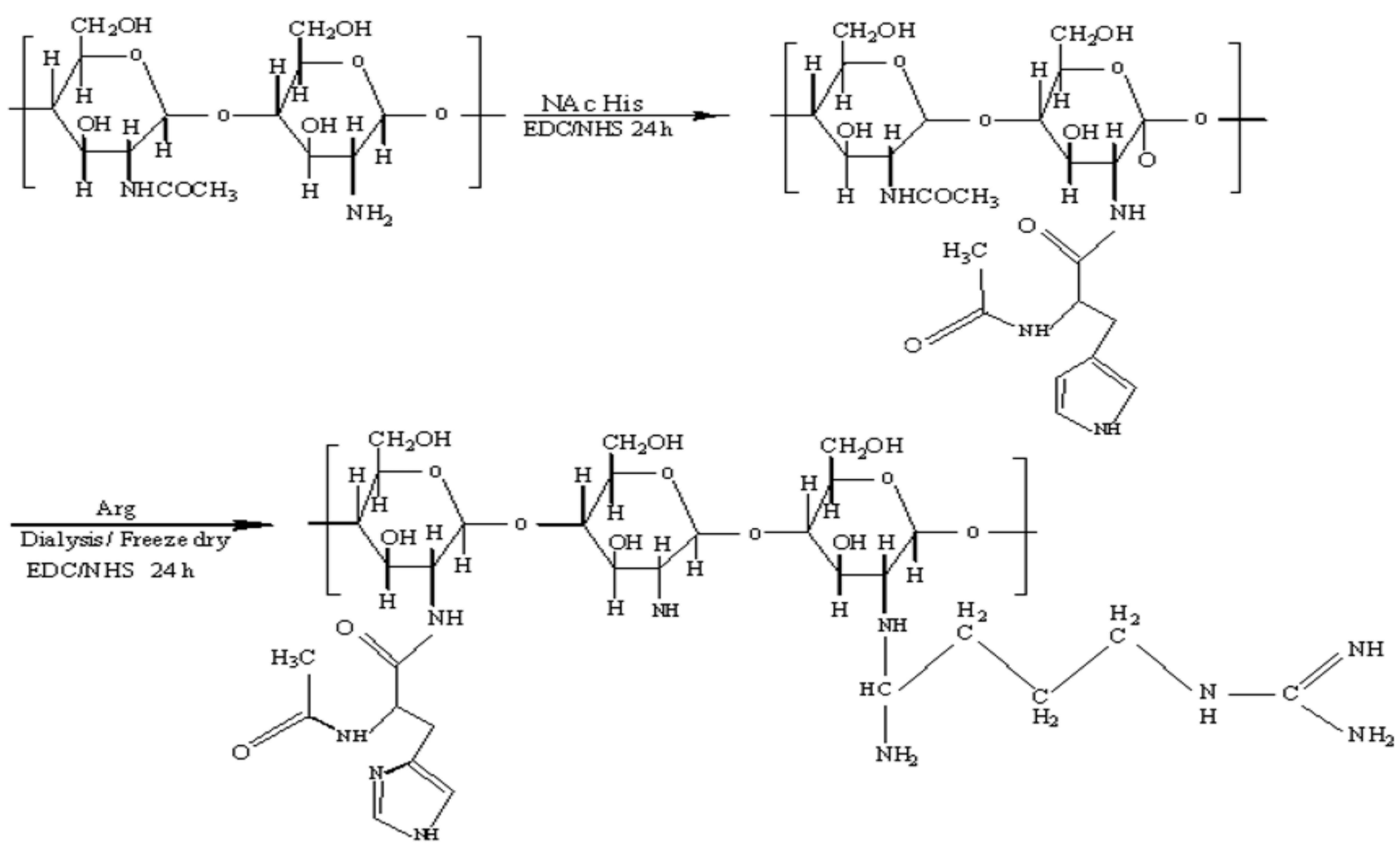

Figure I Synthetic pathway of arginine and N-acetyl histidine modified chitosan (Arg-CS-NAcHis) conjugate.

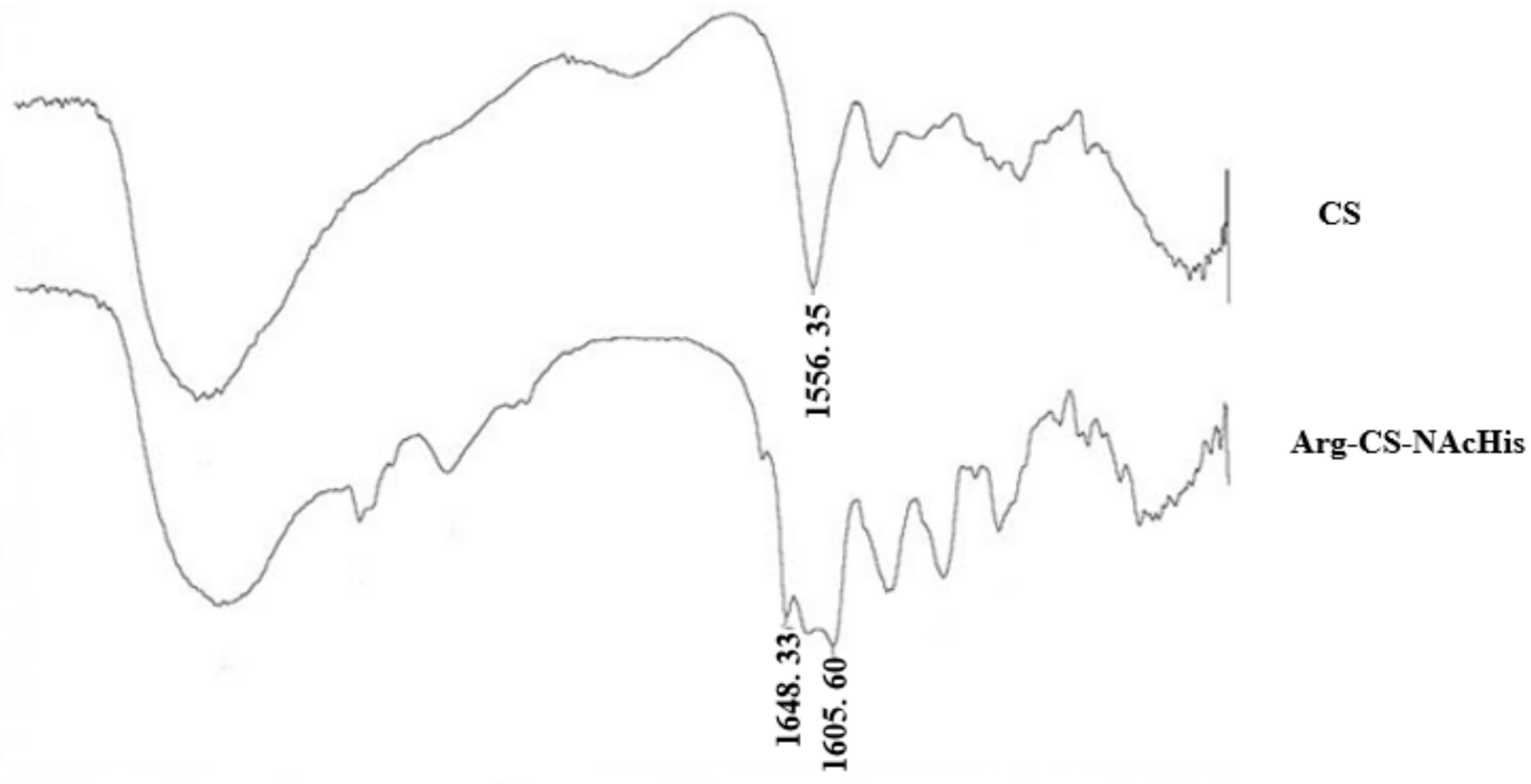

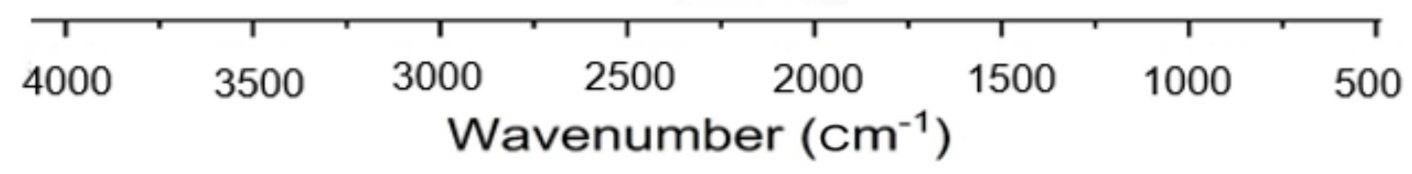

Figure 2 FTIR spectra of chitosan (CS), arginine and N-acetyl histidine-modified chitosan (Arg-CS- NAcHis) conjugate. 


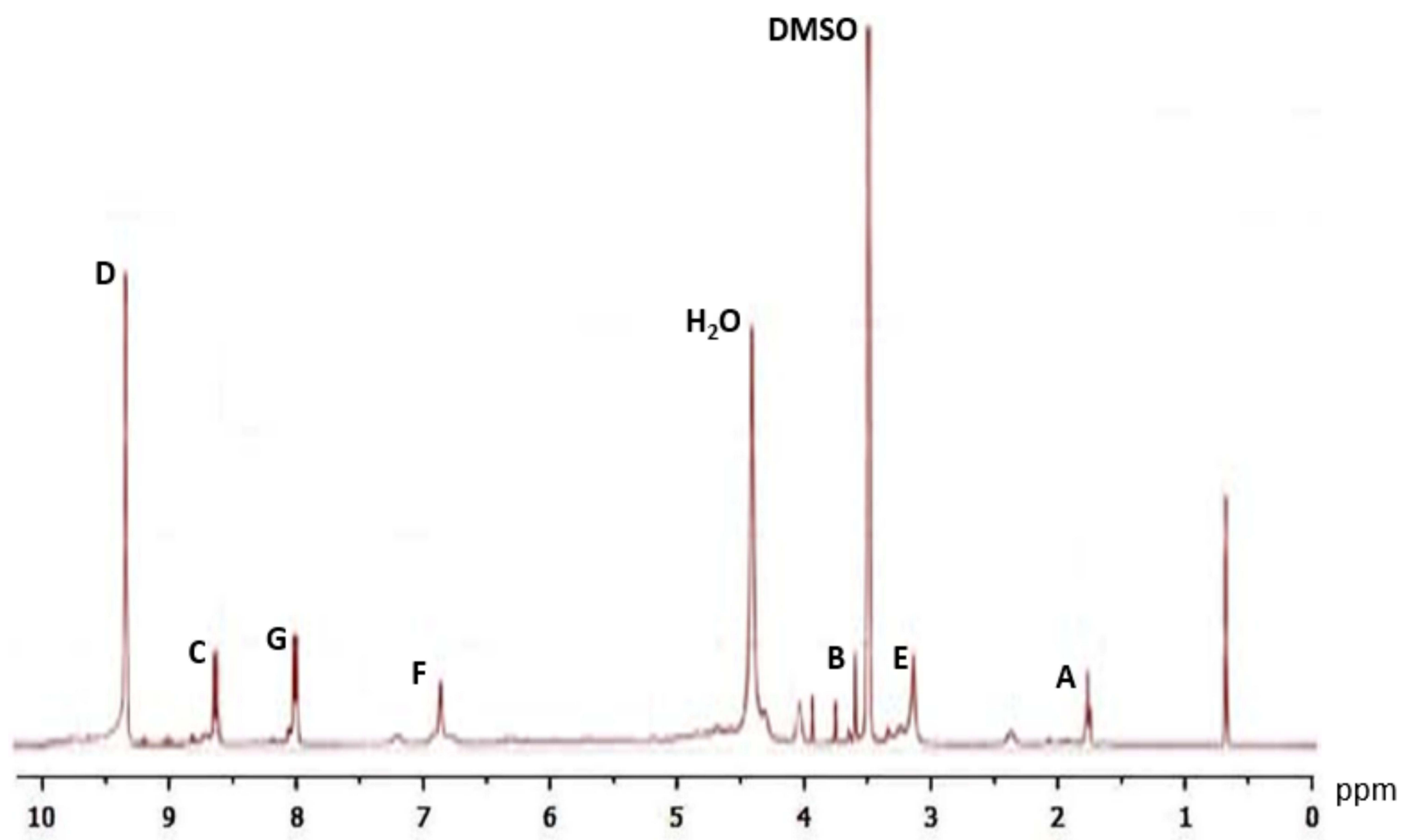

Figure 3 'HNMR spectrum of Arg-CS-NAcHis conjugate.

$\delta \approx 8.00 \mathrm{ppm}(\mathrm{G})$ was attributed to the guanidine functional group present in arginine confirming that this amino acid has been successfully grafted onto chitosan. Moreover, the presence of peaks at $\delta \approx 9.3 \mathrm{ppm}$ showing the imidazole ring in acetyl histidine and also the proton peaks at $\approx 8.6 \mathrm{ppm}$ ascertain its grafting on chitosan backbone.

Based on the above FTIR and ${ }^{1}$ HNMR spectroscopic analysis, it can be demonstrated that both acetyl histidine and arginine have been successfully conjugated on to the chitosan backbone.

\section{Preparation and Characterization of NAcHis-CS-Arg NPs}

The self-assembling or aggregation behavior of arginine and $\mathrm{N}$-acetyl histidine modified chitosan (Arg-CS-NAcHis) NPs in aqueous environment was measured by fluorometry in presence of pyrene as hydrophobic fluorescent probe. When self-assembled structures are formed in aqueous milieu, pyrene tends to be close or enter hydrophobic micro domain and emits strong ground status atomic fluorescence. ${ }^{61}$ The plot in Figure 4 shows the change of intensity ratio (peak $I_{1}$ $/ I_{3}$ ) as a function of concentration of polymeric nanoparticles. The critical micelle concentration (CMC) was determined by the interception of the two straight lines and its value was $0.1 \mathrm{mg} / \mathrm{mL}$ lower as low molecular weight surfactant. This low CAC implies that arginine and N-acetyl histidine modified chitosan (Arg-CS-NAcHis) NPs could be formed at a low polymeric concentration. ${ }^{62-65}$

Transmission electron microscopy was used to confirm the size and shape of the synthesized NPs. Figure 5A shows the TEM image of curcumin encapsulated arginine and N-acetyl histidine modified chitosan (Arg-CS-NAcHis /Cur) NPs showing spherical nanoparticles with in the size range of $200 \mathrm{~nm}$. Size distribution of the prepared nanoparticles is shown in Figure 5B, confirming the formation of well dispersed spherical nanoparticles.

The zeta potential of the synthesized nanoparticles was measured and presented in Figure 5C, the zeta potential of nanoparticles was $39.8 \pm 2.52 \mathrm{mV}$ that could be attributed to the chitosan and dispersion of arginine on the surface of nanoparticles.

\section{Preparation of Curcumin-encapsulated NAcHis-CS-Arg/Cur NPs}

The curcumin-encapsulated arginine and $\mathrm{N}$-acetyl histidine modified chitosan (Arg-CS-NAcHis/Cur) NPs were synthesized with dialysis method and successfully encapsulated "curcumin" the hydrophobic drug inside the 


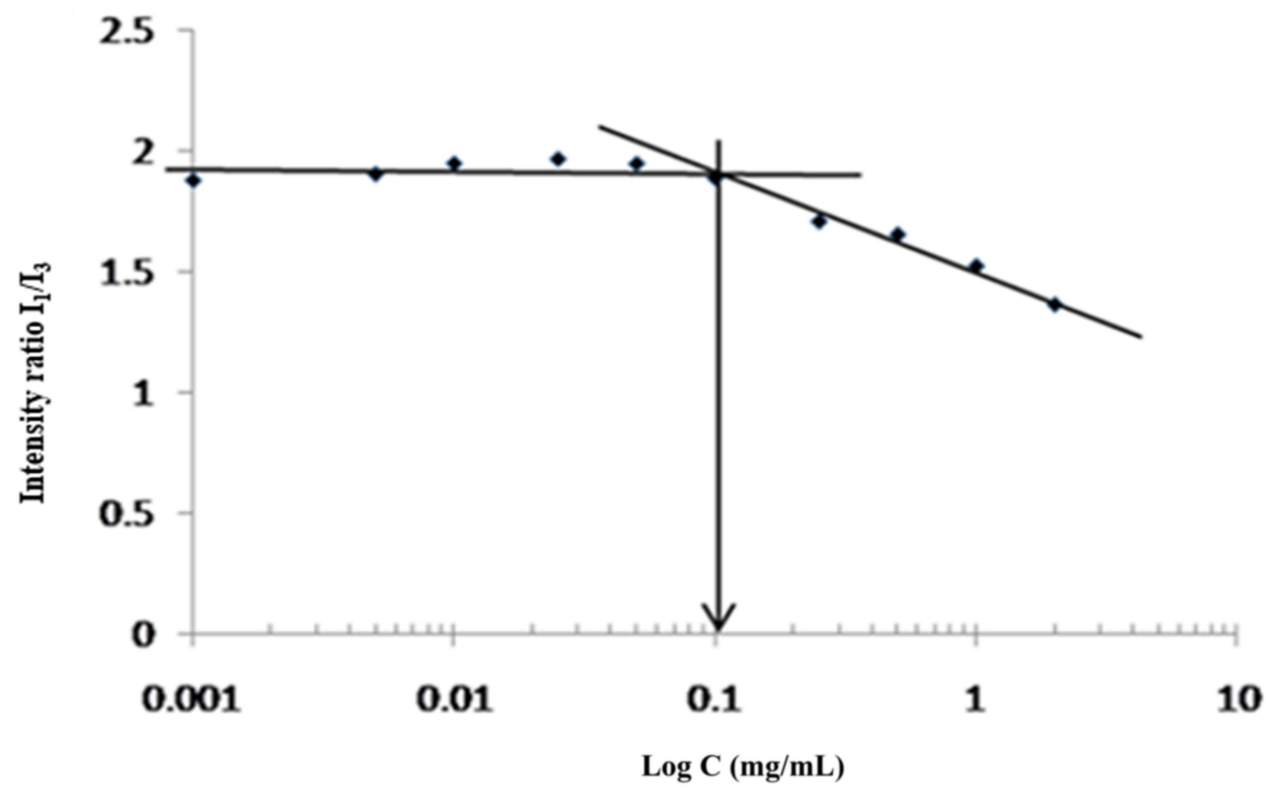

Figure 4 Characteristics of Arg-CS-NAcHis NPs. The variation of fluorescence intensity ratio $I_{1} / I_{3}$ against the logarithm of Arg-CS-NAcHis conjugate concentration in distilled water.
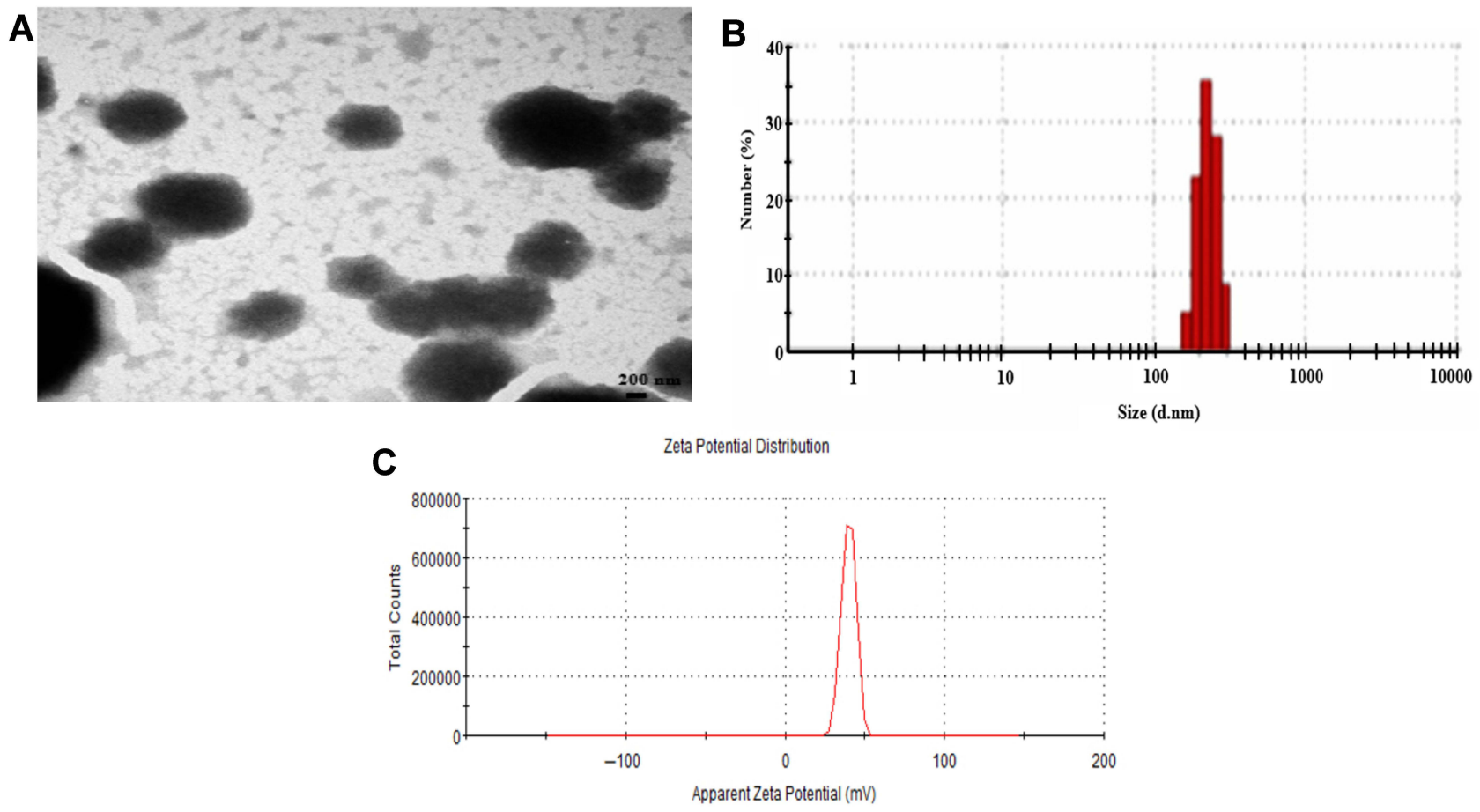

Figure 5 (A) TEM image of Arg-CS-NAcHis/Cur nanoparticles solution. (B) Size distribution of I mg/mL (Arg-CS-NAcHis/Cur) nanoparticles solution. (C) Zeta potential of $\mathrm{I} \mathrm{mg/mL} \mathrm{Arg-CS-NAcHis/Cur} \mathrm{nanoparticle} \mathrm{solution.}$

hydrophobic core. The effects of curcumin feeding concentration on the physicochemical properties like zeta potential, polydispersity index and particle size are summarized in Table 1. As the feeding amount of curcumin was increased from 5 to $15 \mathrm{mg}$, the particle size decreased from $200.6 \pm 8.2 \mathrm{~nm}$ to $170.3 \pm 5.6 \mathrm{~nm}$ as well as polydispersity index value also decreased from $0.378 \pm 0.029$ to $0.295 \pm 0.014$, However, there was no noticeable effect on zeta potential values. Earlier reports of curcumin nanoparticles also showed similar results. 
Table I Characterization of (Arg-CS-NAcHis/Cur) NPs by Varying Drug Concentration

\begin{tabular}{|l|l|l|l|l|}
\hline Curcumin Formulation & Amount of Curcumin in (mg) & Particle Size (nm) & Polydispersity Index (PI) & Zeta Potential (mV) \\
\hline Arg-CS-NAcHis/Cur NP I & 5 & $200.6 \pm 8.2$ & $0.378 \pm 0.029$ & $39.8 \pm 2.52$ \\
Arg-CS-NAcHis/Cur NP 2 & 10 & $180.5 \pm 6.5$ & $0.320 \pm 0.017$ & $35.3 \pm 2.75$ \\
Arg-CS-NAcHis/Cur NP 3 & 15 & $170.3 \pm 5.6$ & $0.295 \pm 0.014$ & $39.1 \pm 1.72$ \\
\hline
\end{tabular}

Moreover, the zeta potential value of nanoparticles was positive, which explains, arginine as hydrophilic positive charged group dispersion on surface of nanoparticles.

Furthermore, it was also observed that with increasing curcumin concentration loading efficiency increased from $6.70 \pm 0.23$ to $28.72 \pm 2.33$ while the encapsulation efficiency (EE) decreased from $78.33 \pm 2.58$ to $66.34 \pm 3.10 \%$ as shown in Table 2.

The loading and encapsulation efficiency of our synthesized nanoparticles were $28.72 \pm 2.33 \%$ and 78.33 $\pm 2.58 \%$, respectively, as noted above. The results obtained here are in agreement with previous reports, ${ }^{66-69}$ and also advocate that curcumin's concentration might be adjusted to get the desired entrapment and loading efficiency.

\section{In vitro Drug Release}

The release behavior of curcumin from the three types of Arg-CS-NAcHis/Cur nanoparticle formulations in simulated intestinal fluids was investigated in vitro and results are shown in Figure 6. Native free drug (used as a control) completed its release quickly and rapidly showing a similar release pattern. We can find a pattern of triphasic drug release in Figure 6; an initial burst release in the first five hours followed by a small plateau and lastly a sustained released effect. Diffusion of curcumin absorbed on surface of the nanoparticles might be responsible for the initial burst type of release. A small plateau in the time period $(5-7 \mathrm{~h})$ might be due to the reason that curcumin on the surface has been stripped, the threedimensional structure of nanoparticles has changed, but the encapsulated curcumin has not released.

Table 2 Encapsulation Efficiency and Loading Efficiency of ArgCS-NAcHis/Cur NPs with Increasing Drug Concentration

\begin{tabular}{|l|l|c|c|}
\hline Curcumin Formulation & $\begin{array}{l}\text { Amount of } \\
\text { Curcumin } \\
\text { (mg) }\end{array}$ & $\begin{array}{c}\text { Encapsulation } \\
\text { Efficiency (\%) }\end{array}$ & $\begin{array}{c}\text { Loading } \\
\text { Efficiency } \\
\text { (\%) }\end{array}$ \\
\hline Arg-CS-NAcHis/Cur NP I & 5 & $55.27 \pm 2.84$ & $6.70 \pm 0.23$ \\
Arg-CS-NAcHis/Cur NP 2 & 10 & $78.33 \pm 2.58$ & $15.13 \pm 1.60$ \\
Arg-CS-NAcHis/Cur NP 3 & 15 & $66.34 \pm 3.10$ & $28.72 \pm 2.33$ \\
\hline
\end{tabular}

The above results conclude that compared to free curcumin, the synthesized nanoparticles sustained release capacity reaches $85 \%$ peak release in $24 \mathrm{~h}$, while free curcumin completed all its release rapidly. Disintegration of polymer materials and drug diffusion could be explained as mechanism of curcumin release from nanoparticles. $^{70}$

\section{In vitro Cytotoxicity Study}

Earlier reports ${ }^{71}$ have demonstrated that curcumin possess cytotoxic potential and the groups $[-\mathrm{OH}]$ and $[-$ $\mathrm{OMe}]$ are responsible for its antiproliferative and antioxidant properties, respectively. In order to confirm whether encapsulation of curcumin in arginine and $\mathrm{N}$-acetyl histidine modified chitosan (Arg-CS-NAcHis/Cur) NPs can exert any effects on the intrinsic cytotoxic potential of curcumin, the cytotoxicity of Arg-CS-NAcHis/Cur NPs were evaluated with KGN cells (a human granular carcinoma cell line). KGN cells were exposed to equivalent concentration of free and encapsulated curcumin NPs and cell viability was quantified by MTT assay. Results drawn in Figure 7 shows that blank Arg-CS-NAcHis/Cur NPs has no harmful effects on cells (control yellow bar) compared to the untreated cells (control green bar); both free curcumin and curcumin encapsulated nanoparticles Arg-CS-NAcHis/Cur NPs showed a dose-dependent cytotoxic effect. The $\mathrm{IC}_{50}$ calculated for free and encapsulated curcumin (Arg-CS-NAcHis/Cur) NPs and free curcumin were found to be $27.50 \mu \mathrm{mol} / \mathrm{L}$ and 17.30 $\mu \mathrm{mol} / \mathrm{L}$, respectively. No noticeable cytotoxic effect was observed for two formulations of curcumin at concentration of $2.5 \mu \mathrm{mol} / \mathrm{L}$. However, the cytotoxicity of Arg-CSNAcHis/Cur NPs increased significantly at curcumin concentrations above $5 \mu \mathrm{mol} / \mathrm{L}(p<0.05)$. Here, we opine that native curcumin due to its poor aqueous solubility, instability, and precipitation results in low cytotoxic activity. Whereas, the nanoparticles have better cytotoxic profile due to increased solubility, better cellular uptake, and improved stability at physiological $\mathrm{pH}$. Previous studies have reported arginine as a potential agent for drug delivery due to its ability to 


\section{- Free Curcumin \\ - Arg-CS-NAcHis/Cur NPs 1 \\ $\leftarrow$ Arg-CS-NAcHis/Cur NPs 2 \\ $\rightarrow$ Arg-CS-NAcHis/Cur NPs 3}

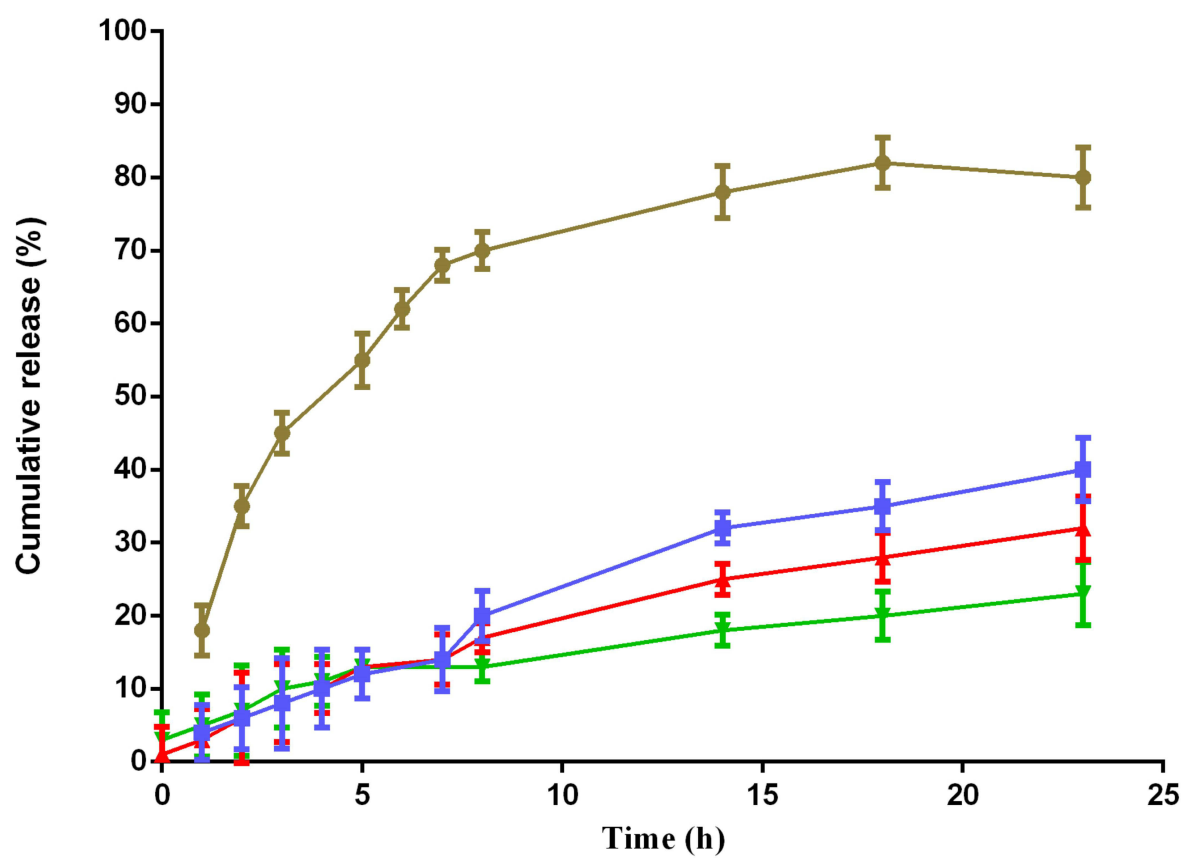

Figure 6 Sustained release pattern of curcumin from the drug-loaded nanoparticles.

improve cellular internalization and enhance permeation effects with little cytotoxicity. ${ }^{72-74}$

\section{Intracellular Uptake Study}

An important aspect for evaluation of potential drug delivery system is cellular uptake. This will shed light on whether the system is effective in vivo. So, to further confirm the relationship between the cytotoxic potential (as outlined above) and cellular uptake, KGN cells (a human granular carcinoma cell line) were incubated for three hours at physiological temperature of $37^{\circ} \mathrm{C}$ with native curcumin and Arg-CS-NAcHis/Cur NPs, respectively at an equal concentration of $7.3 \mu \mathrm{g}$ / $\mathrm{mL}$. As presented in Figure 8A-D, it was observed that compared with cells treated with bare curcumin, the cells exposed to nanoparticles solution showed the strongest green fluorescence. Whereas, the fluorescence of cells treated with free curcumin was faintly visible. These results are consistent with previous reports and prove that the curcumin nanoparticles formulation is more effective in enhancement of curcumin uptake. $^{75,76}$

\section{Effects of the Synthesized Arg-CS- $\mathrm{NAcH}$ is/Cur NPs on EV Induced PCOS in Female Wistar Rats}

The major goal of this study was to evaluate the effects of the synthesized nanoparticles compared with native curcumin on EV-induced PCOS rats by analyzing the biochemical and histopathological parameters in detail.

\section{Effects on the Estrous Cycle}

The polycystic ovaries in the experimental groups of animals were detected by the irregularity of the estrous cycle through the vaginal smears method. In order to confirm the occurrence of PCOS, samples collected at different stages of the estrous cycle were analyzed in all the treatment groups. Table 3 shows that the proestrus phase was dominant $(26.4 \pm 0.7)$ in the control group, the untreated group of PCOS presents estrous cycle irregularity mostly at the stage of tha diestrus phase (40.3 \pm 1.7 ), which is also persistent compared to the estrous cycles in other groups and is also an indication for anovulation. The group treated with metformin as 


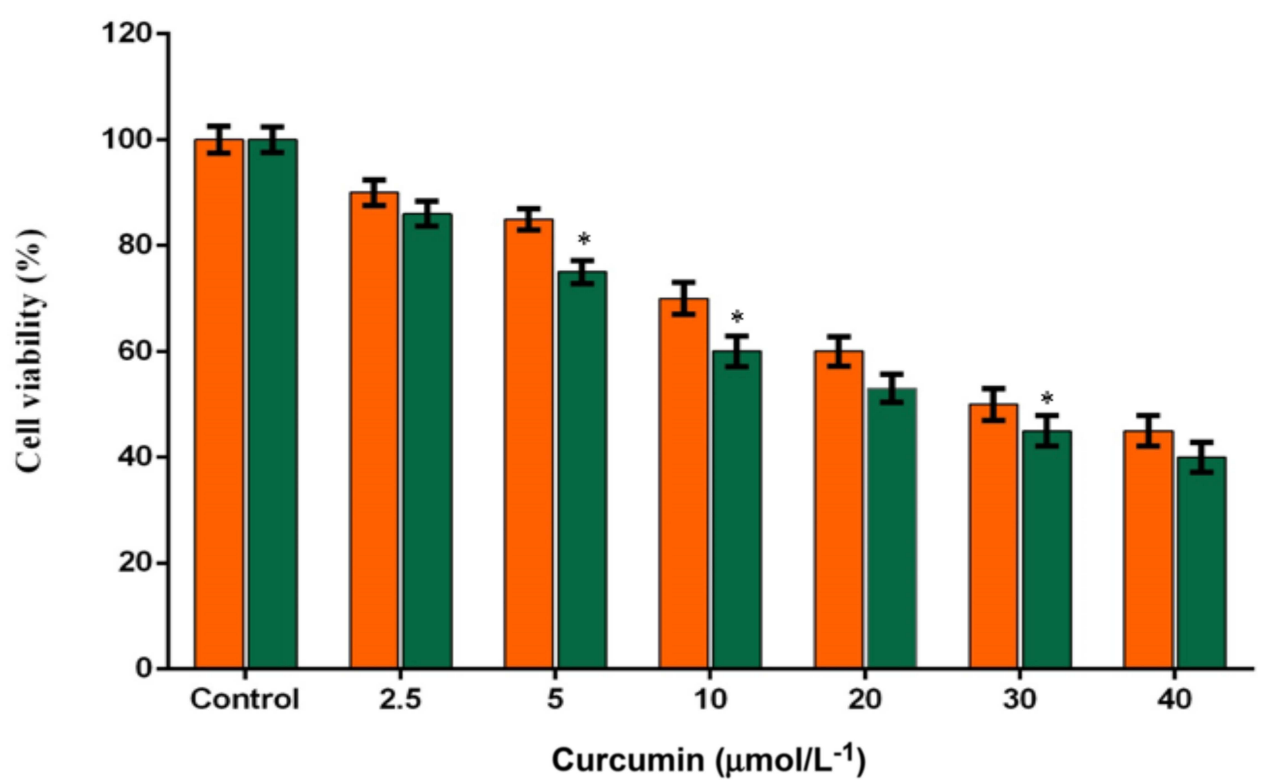

Figure 7 Cytotoxicity effect of different concentrations of Arg-CS-NAcHis/Cur NPs in KGN cells. Data are presented as the means \pm standard deviation from three independent experiments. $* p<0.05$ compared with free curcumin solution.

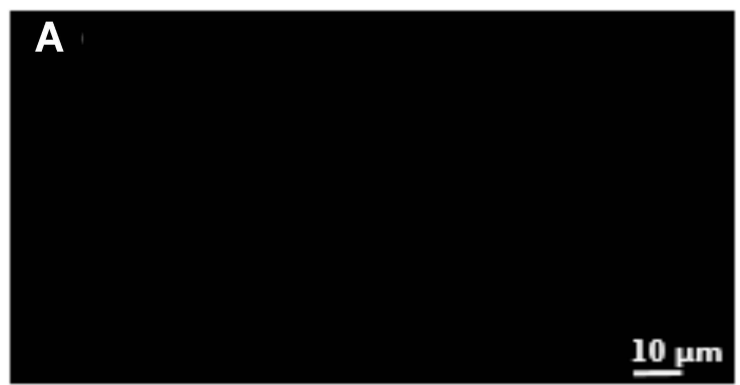

Control

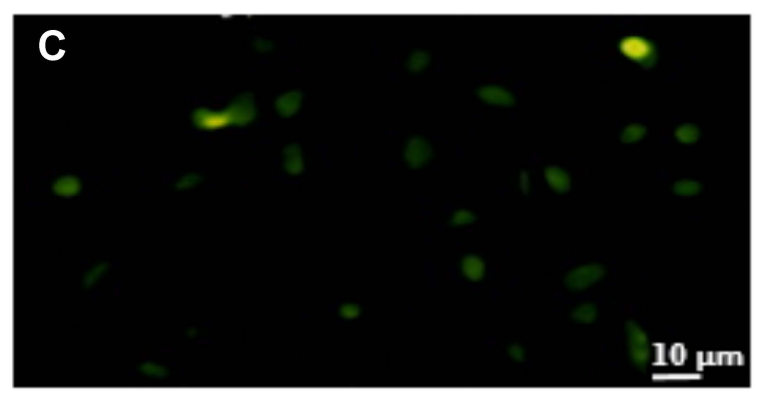

Free Curcumin

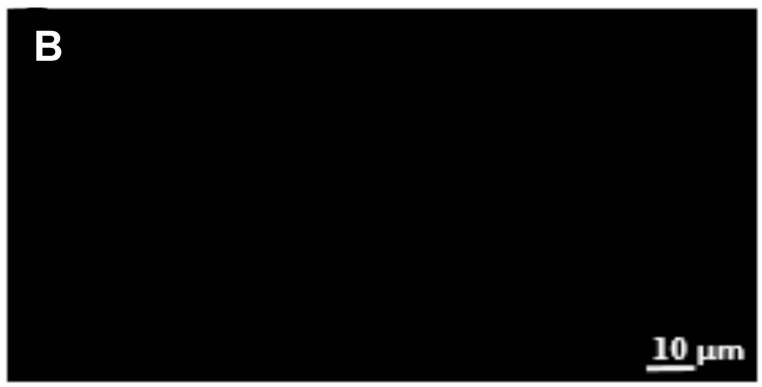

Empty Arg -CS-NAcHis NPs

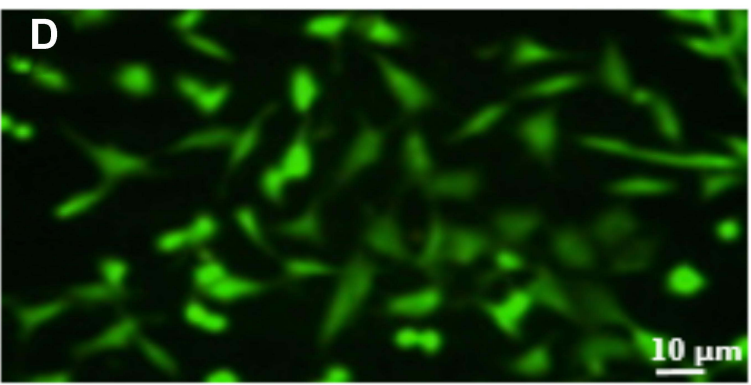

Arg-CS-NAcHis/Cur NPs

Figure 8 Fluorescence microscopic images for the KGN cells uptake of free curcumin and Arg-CS-NAcHis/Cur NPs after incubation with $7.3 \mu \mathrm{g} / \mathrm{mL}$ at $37^{\circ} \mathrm{C}$ for 3 h. $(\mathbf{A})$ Fluorescence images of control cells (without any treatment); (B) cells treated with blank AN Arg-CS-NAcHis NPs; (C) cells treated with free Cur solution; and (D) cells treated with Arg-CS-NAcHis/Cur Np. 
Table 3 The Percentage of Rats at Each Stage of the Estrous Cycle in Different Treatment Groups After 2I Days of Treatment

\begin{tabular}{|l|c|c|c|c|}
\hline Treatment Groups & Proestrus (\%) & Estrus (\%) & Metestrus (\%) & Diestrus (\%) \\
\hline Control & $26.4 \pm 0.7$ & $23.1 \pm 1.2$ & $24.1 \pm 0.6$ & $24.3 \pm 0.5$ \\
PCOS-induced & $20.5 \pm 1.3$ & $17.2 \pm 1.3$ & $24.4 \pm 1.4$ & $40.3 \pm 1.7$ (Persistent) \\
Metformin & $22.1 \pm 0.9$ & $22.6 \pm 1.1$ & $25.8 \pm 1.7$ & $23.7 \pm 1.5$ \\
Curcumin & $27.3 \pm 1.1$ & $25.8 \pm 0.8$ & $22.3 \pm 1.6$ & $20.7 \pm 1.8$ \\
Arg-CS-NAcHis/Cur NPs & $30.7 \pm 1.6$ & $35.6 \pm 1.5$ & $28.7 \pm 1.3$ & $25.3 \pm 1.4$ \\
\hline
\end{tabular}

standard drug shows the metestrus stage as the prominent phase of the cycle. Predominant proestrus stage was observed in the curcumin treated group whereas estrus phase was observed as the predominant phase $(35.6 \pm 1.5)$ in the groups treated with nanoparticles. Previous research studies ${ }^{77,78}$ also reported similar effects on the estrous cycle with different suggested protocol.

\section{Effects on Gonadotropic Hormone Levels}

In order to evaluate the effects of the synthesized NPs on hormone levels in PCOS induced rat model, the levels of follicle stimulating hormone (FSH); luteinizing hormone $(\mathrm{LH})$; testosterone $(\mathrm{T})$; progesterone $(\mathrm{PRG})$; prolactin
(PRO) and insulin (INS) were determined in serum samples collected from all the animal groups after 21 days.

As illustrated in Figure 9A-F; It was observed that LH level decreased from $0.695 \mathrm{mIU} / \mathrm{mL}$ (PCOS group) to $0.560 \mathrm{mIU} / \mathrm{mL}$ after treatment of PCOS rats with synthesized NPs. Quite the opposite, the level of progesterone was increased than PCOS untreated groups. The progesterone level was elevated from the value of $4.680 \mathrm{ng} / \mathrm{mL}$ to $8.750 \mathrm{ng} / \mathrm{mL}$. A similar increasing pattern of progesterone level was also observed for metformin and curcumin treated groups. The level of prolactin hormone was found to be decreased in PCOS rats by treating with metformin and curcumin. Interestingly, it was observed that the level of prolactin was significantly decreased in the
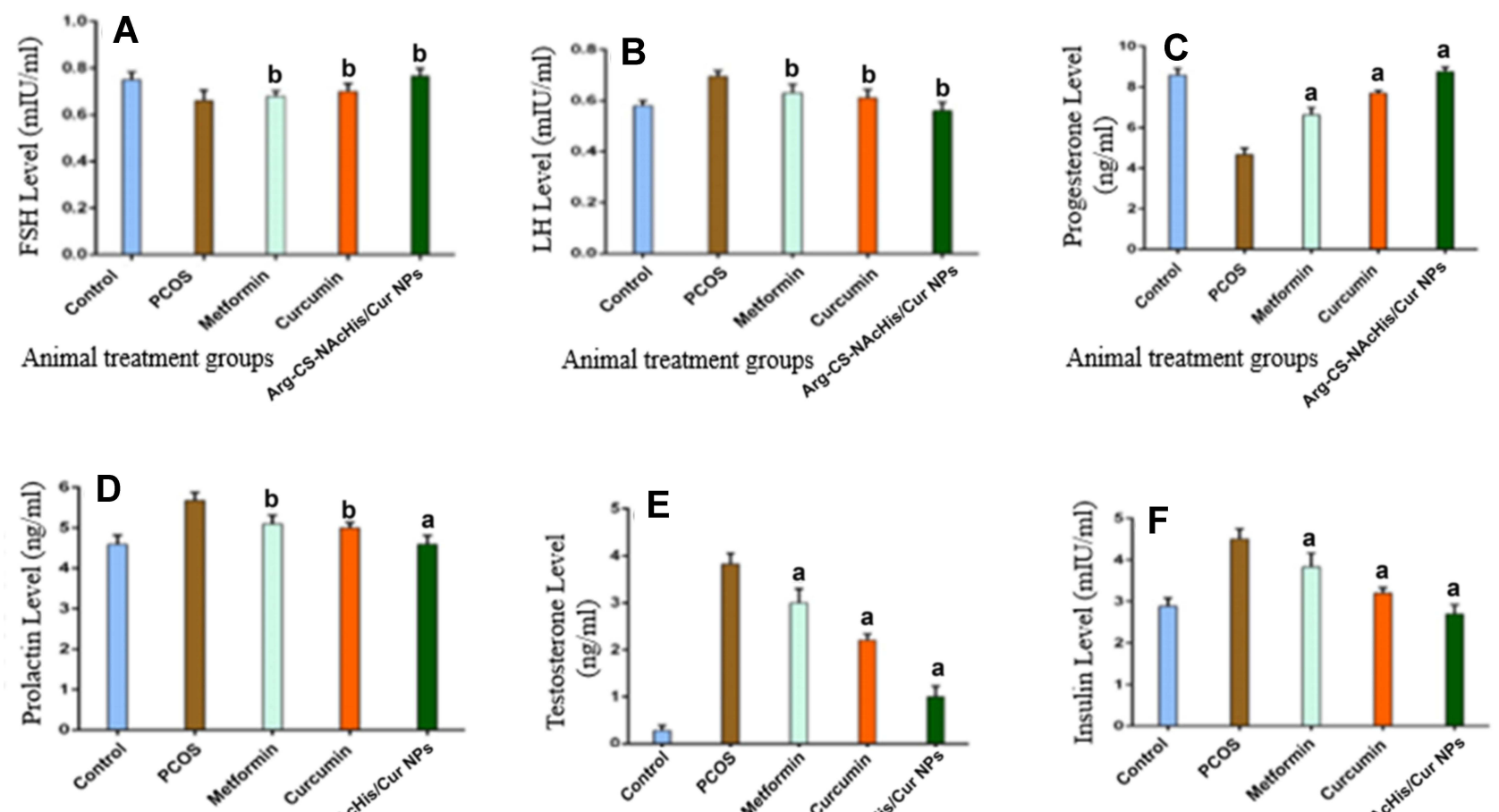

Animal treatment groups
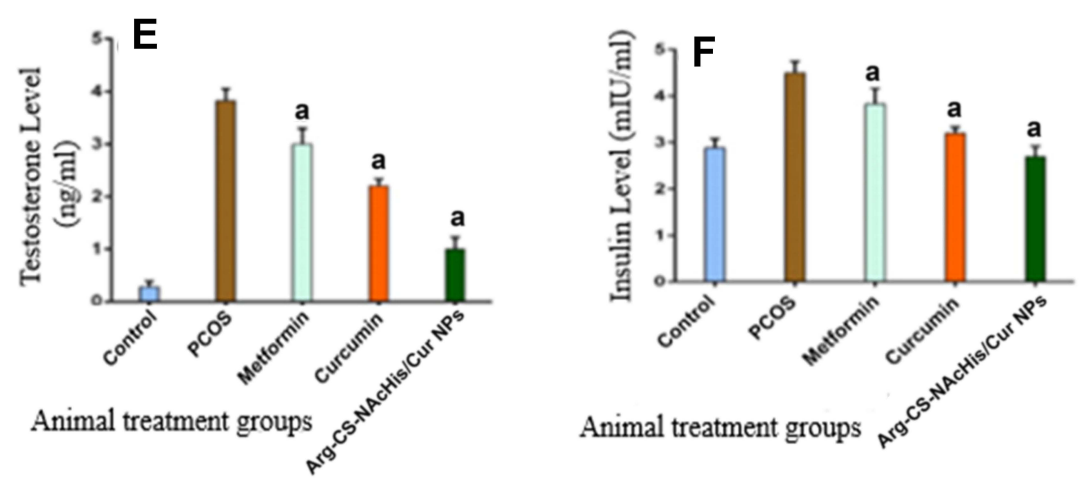

Figure 9 Determination of the level of (A) FSH, (B) LH, (C) PRG, (D) PRO, (E) testosterone and (F) INS in PCOS induced rats after treatment with metformin, curcumin, and synthesized Arg-CS-NAcHis/Cur nanoparticles. Values are statistically significant at $p<0.05$ by ANOVA test. ${ }^{a}$ Significantly differ from PCOS, ${ }^{b}$ nonsignificant vs PCOS. 
nanoparticle-treated groups compared to the PCOS model. As clearly demonstrated in Figure 9F the level of insulin was downregulated by nanoparticle treatment compared to the PCOS model. It was also noticed that nanoparticles were more potent in decreasing the insulin level than metformin and curcumin. It was evident from figure Figure 9E that the level of testosterone was increased in the PCOS model compared to the control group; however, by the treatment of metformin, curcumin, and nanoparticles there was a decreasing pattern in the testosterone level. Furthermore, it was also observed in our studies that there was no significant difference in FSH concentrations in all the experimental groups. The results we report here are in agreement with previously published studies. ${ }^{78,79}$ From the above results, we can conclude that NPs have better potential in managing hormone levels in PCOS rats.

\section{Histopathological Changes in Ovaries}

The effects of the synthesized Arg-CS-NAcHis/Cur NPs in relation to curcumin and metformin were observed on morphology of the ovaries collected from the experimental mice after 21 days of treatment. As shown in Figure 10A-E, the development of corpus luteum and normal matured structured follicles were seen in the ovaries of the control group under microscopic examinations. The increased corpus luteum is also an indication for ovulation induction. Ovarian sections from the untreated PCOS group exhibit a large number of cystic follicles with a thin granulosa layer. Reduced number of corpus luteum was also found in EV-induced PCOS rats which is an indication for reduction of ovulation rate. However, development of normal follicular structures were seen in metformin-treated groups. The effects of native drug "curcumin" is also presented in Figure 10C, which shows positive effects on ovarian morphology. Interestingly, it was observed that treatment with Arg-CSNAcHis/Cur NPs changed the PCOS ovarian morphology to normal morphology. Moreover, well-structured follicles were seen in normalization process after treatment of PCOS rats with nanoparticles.

Furthermore, the development of corpus luteum in PCOS rats after nanoparticle treatment suggests that the estrus cyclicity was restored back to normal after treatment with drug-loaded nanoparticles. It could be clearly seen that cysts had disappeared and normal follicle formation was restored after treatment (Figure 10). Compared to free drug curcumin

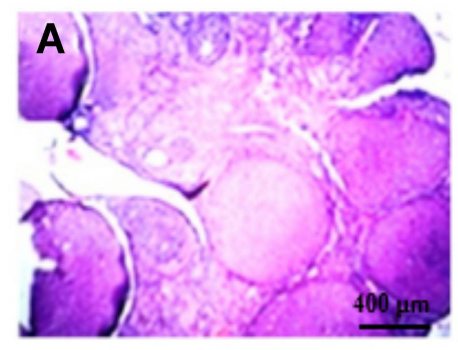

Control Group

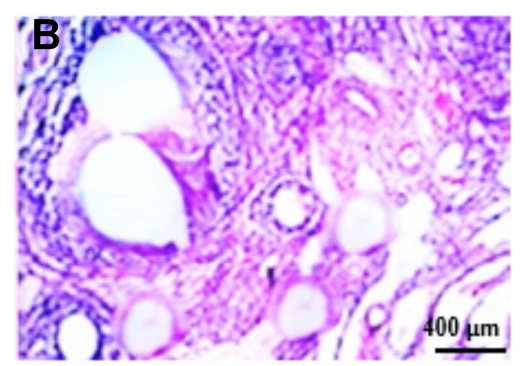

PCOS Group

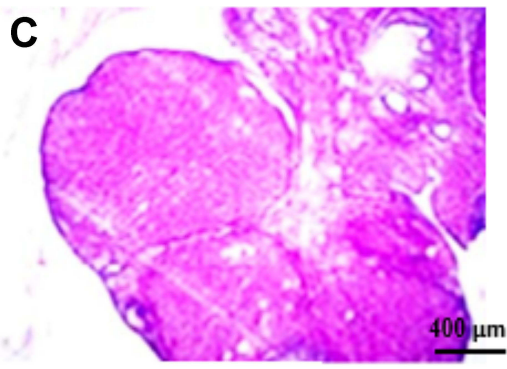

Curcumin Group

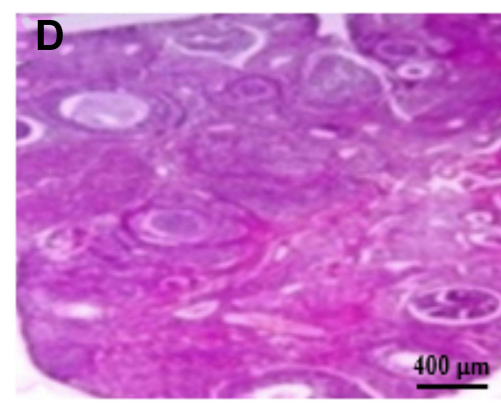

Metformin Group

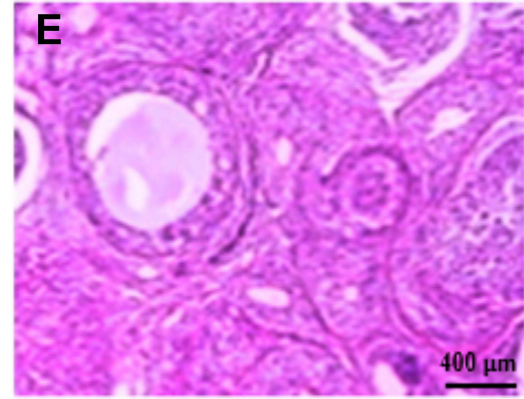

Arg-CS-NAcHis/Cur NPs Group

Figure 10 Histopathological changes in ovaries of different experimental groups. (A) Ovarian section from the control group mice, (B) ovarian section from the PCOSinduced untreated group mice, (C) ovarian section from the curcumin-treated group mice, (D) ovarian section from the metformin-treated group mice, (E) ovarian section from the CS-NAcHis/Cur NPs treated group mice. 
and standard drug metformin the developed nanoparticles were more effective in restoration of PCOS morphology.

\section{Conclusion}

In this study, chitosan was modified with hydrophilic arginine (Arg) and hydrophobic N-acetyl histidine (NAcHis) group (Arg-CS-NAcHis). The modified polymer was analyzed with FTIR and NMR studies. Based on modified chitosan polymer, self-assembled curcumin-encapsulated nanoparticles were fabricated via dialysis method and characterized for physicochemical properties. TEM analysis shows spherical nanoparticles with average size of $200 \mathrm{~nm}$. In vitro drug release showed sustained release pattern in biological fluids. Cytotoxicity and cellular uptake studies revealed that there was preferential uptake of nanoparticles compared to free drug curcumin. The synthesized nanoparticles in comparison to free drug curcumin and metformin were then evaluated for their protective and therapeutic effects in PCOS rats and different hormone levels such as FSH, LH, PRO, testosterone and insulin were determined. The results showed that the PCOS group treated with nanoparticles showed a reverting pattern of estrous cycle back to normal compared to control group. Furthermore, it was observed that nanoparticles were also effective in decreasing serum $\mathrm{LH}$, prolactin, testosterone and insulin levels. However, increased level of FSH and progesterone in PCOS from that of the control was observed. Moreover, it was observed that nanoparticles maintained a balanced gonadotrophic hormone level and formation of corpus luteum and follicles in the PCOS group. Furthermore, the results also showed that nanoparticles were comparable with metformin in treatment of PCOS and led to recovery of regular ovulation and fertility in PCOS rats. In future, these nanoparticles may provide a platform for discussion in better management of PCOS. To the best of our knowledge, this is amongst the very first reports on nanoparticulate-mediated treatment for PCOS.

\section{Acknowledgments}

This study was supported by grant funding from Chengdu Jinxin Research Institute for Reproductive Medicine and Genetics, Chengdu Jinjiang Hospital for Maternal and Child Health Care, Chengdu, China. (Y2019006).

\section{Disclosure}

The authors report no conflicts of interest in this work.

\section{References}

1. van Houten EL, Visser JA. Mouse models to study polycystic ovary syndrome: a possible link between metabolism and ovarian function? Reprod Biol. 2014;14(1):32-43. doi:10.1016/j.repbio.2013.09.007

2. Aghaie F, Khazali H, Hedayati M, Akbarnejad A. The effects of exercise on expression of CYP19 and StAR mRNA in steroid-induced polycystic ovaries of female rats. Int $J$ Fertility Sterility. 2018;11(4):298.

3. Yao K, Bian C, Zhao X. Association of polycystic ovary syndrome with metabolic syndrome and gestational diabetes: aggravated complication of pregnancy. Exp Ther Med. 2017;14(2):1271-1276. doi:10.3892/etm.2017.4642

4. Moran LJ, Misso ML, Wild RA, Norman RJ. Impaired glucose tolerance, type 2 diabetes and metabolic syndrome in polycystic ovary syndrome: a systematic review and meta-analysis. Hum Reprod Update. 2010;16(4):347-363. doi:10.1093/humupd/dmq001

5. Sri SB, Sathiyawathie RS, Gurunathan D. Hormonal imbalance due to polycystic ovarian syndrome. Drug Invention Today. 2019;12:3.

6. Azziz R, Yildiz B, Woods KS, et al. The prevalence of polycystic ovary syndrome among unselected consecutive premenopausal women. J Clin Endocrinol Metab. 2004;89:2745-2749. doi:10. 1210/jc.2003-032046

7. Fauser BC, Tarlatzis BC, Rebar RW, et al. Consensus on women's health aspects of polycystic ovary syndrome (PCOS). Fertility Sterility. 2012;97:28-38

8. Hart R, Doherty DA. The potential implications of a PCOS diagnosis on a woman's long-term health using data linkage. J Clin Endocrinol Metab. 2015;100(3):911-919. doi:10.1210/jc.2014-3886

9. Daan NM, Louwers YV, Koster MP, et al. Cardiovascular and metabolic profiles amongst different polycystic ovary syndrome phenotypes: who is really at risk? Fertil Steril. 2014;102(5):1444-1451. doi:10.1016/j.fertnstert.2014.08.001

10. De Leo V, Musacchio MC, Cappelli V, Massaro MG, Morgante G, Petraglia F. Genetic, hormonal and metabolic aspects of PCOS: an update. Reprod Biol Endocrinol. 2016;14(1):38. doi:10.1186/s12958016-0173-x

11. Aa JH, Feeley CA, Kf WK. Low-dose tacrolimus prevents dysregulated peri-conceptional ovarian and systemic immune cellular homeostasis in subjects with PCOS. Sci Rep. 2019;9(1):1-8.

12. Baker S, Satish S. Endophytes: toward a vision in synthesis of nanoparticle for future therapeutic agents. Int $J$ Bio-Inorg Hybd Nanomat. 2012;1(2):67-77.

13. Jaybhaye SV. Antimicrobial activity of silver nanoparticles synthesized from waste vegetable fibers. Mater Today Proc. 2015;2 (9):4323-4327.

14. Tiwari PM, Vig K, Dennis VA, Singh SR. Functionalized gold nanoparticles and their biomedical applications. Nanomaterials. 2011;1(1):31-63. doi:10.3390/nano1010031

15. Malafaya PB, Santos TC, van Griensven M, Reis RL. Morphology, mechanical characterization and in vivo neo-vascularization of chitosan particle aggregated scaffolds architectures. Biomaterials. 2008;29(29):3914-3926. doi:10.1016/j.biomaterials.2008.06.023

16. Muzzarelli C, Stanic V, Gobbi L, Tosi G, Muzzarelli RA. Spraydrying of solutions containing chitosan together with polyuronans and characterisation of the microspheres. Carbohydr Polym. 2004;57(1):73-82. doi:10.1016/j.carbpol.2004.04.002

17. Gao Y, Xu Z, Chen S, Gu W, Chen L, Li Y. Arginine-chitosan/DNA self-assemble nanoparticles for gene delivery: in vitro characteristics and transfection efficiency. Int $J$ Pharm. 2008;359(1-2):241-246. doi:10.1016/j.ijpharm.2008.03.037

18. Jayakumar R, Prabaharan M, Reis RL, Mano J. Graft copolymerized chitosan-present status and applications. Carbohydr Polym. 2005;62 (2):142-158. doi:10.1016/j.carbpol.2005.07.017 
19. Jayakumar R, Nwe N, Tokura S, Tamura H. Sulfated chitin and chitosan as novel biomaterials. Int J Biol Macromol. 2007;40 (3):175-181. doi:10.1016/j.ijbiomac.2006.06.021

20. Shelma R, Sharma CP. In vitro and in vivo evaluation of curcumin loaded lauroyl sulphated chitosan for enhancing oral bioavailability. Carbohydr Polym. 2013;95(1):441-448. doi:10.1016/j.carbpol.2013. 02.029

21. Casettari L, Vllasaliu D, Lam JK, Soliman M, Illum L. Biomedical applications of amino acid-modified chitosans: a review. Biomaterials. 2012;33(30):7565-7583. doi:10.1016/j.biomaterials.20 12.06.104

22. Masha A, Manieri C, Dinatale S, Bruno GA, Ghigo E, Martina V. Prolonged treatment with $\mathrm{N}$ - acetylcysteine and L-arginine restores gonadal function in patients with polycystic ovary syndrome. J Endocrinol Invest. 2009;32(11):870-872. doi:10.1007/BF03345763

23. Feng RN, Niu YC, Sun XW, et al. Histidine supplementation improves insulin resistance through suppressed inflammation in obese women with the metabolic syndrome: a randomised controlled trial. Diabetologia. 2013;56(5):985-994. doi:10.1007/s00125-0132839-7

24. Wade AM, Tucker HN. Antioxidant characteristics of L-histidine 11The work described in this manuscript was partially sponsored and funded by Cytos Pharmaceuticals, LLC. J Nutr Biochem. 1998;9(6):308-315. doi:10.1016/S0955-2863(98)00022-9

25. Chu WK, Cheung SC, Lau RA, Benzie IF. Bilberry (Vaccinium myrtillus L.). Herbal Med. 2011;20115386:55-71.

26. Al-Romaiyan A, King AJ, Persaud SJ, Jones PM. A novel extract of Gymnema sylvestre improves glucose tolerance in vivo and stimulates insulin secretion and synthesis in vitro. Phytotherapy Res. 2013;27(7):1006-1011. doi:10.1002/ptr.4815

27. Arentz S, Abbott JA, Smith CA, Bensoussan A. Herbal medicine for the management of polycystic ovary syndrome (PCOS) and associated oligo/amenorrhoea and hyperandrogenism; a review of the laboratory evidence for effects with corroborative clinical findings. BMC Complement Altern Med. 2014;14(1):511. doi:10.1186/14726882-14-511

28. Pages ES, Tarlatzis BC, Rebar RW. Consensus on women's health aspects of polycystic ovary syndrome (PCOS). Hum Reprod. 2012;27 (1):14-24. doi:10.1093/humrep/der396

29. Messinis IE. Ovulation induction: a mini review. Human Reproduction. 2005;20(10):2688-2697. doi:10.1093/humrep/dei128

30. Tang T, Lord JM, Norman RJ, Yasmin E, Balen AH. Insulin-sensitising drugs (metformin, rosiglitazone, pioglitazone, D-chiro-inositol) for women with polycystic ovary syndrome, oligo amenorrhoea and subfertility. Cochrane Database Syst Rev. 2010;1:2-12.

31. Maharjan R, Nagar PS, Nampoothiri L. Effect of Aloe barbadensis Mill. formulation on Letrozole induced polycystic ovarian syndrome rat model. J Ayurveda Integr Med. 2010;1(4):273. doi:10.4103/09759476.74090

32. Farideh ZZ, Bagher M, Ashraf A, Akram A, Kazem M. Effects of chamomile extract on biochemical and clinical parameters in a rat model of polycystic ovary syndrome. J Reprod Infertil. 2010;11 (3):169-174.

33. Merrily A, Winston D. Herbal Therapy \& Supplements. Philadelphia: Lippencott; 2002.

34. Aggarwal BB, Harikumar KB. Potential therapeutic effects of curcumin, the anti-inflammatory agent, against neurodegenerative, cardiovascular, pulmonary, metabolic, autoimmune and neoplastic diseases. Int J Biochem Cell Biol. 2009;41(1):40-59. doi:10.1016/j.biocel.2008.06.010

35. Lin MS, Lee YH, Chiu WT, Hung KS. Curcumin provides neuroprotection after spinal cord injury. J Surg Res. 2011;166(2):280-289. doi:10.1016/j.jss.2009.07.001

36. Aggarwal BB, Sung B. Pharmacological basis for the role of curcumin in chronic diseases: an age- old spice with modern targets. Trends Pharmacol Sci. 2009;30(2):85-94. doi:10.1016/j.tips.2008.11.002
37. Mythri RB, Harish G, Dubey SK, Misra K, Bharath MS. Glutamoyl diester of the dietary polyphenol curcumin offers improved protection against peroxynitrite-mediated nitrosative stress and damage of brain mitochondria in vitro: implications for Parkinson's disease. Mol Cell Biochem. 2011;347(1-2):135-143. doi:10.1007/s11010-010-0621-4

38. Raja MA, Zeenat S, Arif M, Liu C. Self-assembled nanoparticles based on amphiphilic chitosan derivative and arginine for oral curcumin delivery. Int J Nanomedicine. 2016;11:4397. doi:10.2147/IJN.S106116

39. Ali raja M, Liu C, Huang Z. Nanoparticles based on oleate alginate ester as curcumin delivery system. Curr Drug Deliv. 2015;12 (5):613-627. doi:10.2174/1567201812666150511095029

40. Escobar-Morreale HF, Botella-Carretero JI, Villuendas G, Sancho J, San Millán JL. Serum interleukin-18 concentrations are increased in the polycystic ovary syndrome: relationship to insulin resistance and to obesity. J Clin Endocrinol Metab. 2004;89(2):80611. doi:10.1210/ jc.2003-031365

41. Toulis KA, Goulis DG, Mintziori G, et al. Meta-analysis of cardiovascular disease risk markers in women with polycystic ovary syndrome. Hum Reprod Update. 2011;17(6):741-760. doi:10.1093/humupd/dmr025

42. Escobar-Morreale HF, Luque-Ramírez M, González F. Circulating inflammatory markers in polycystic ovary syndrome: a systematic review and metaanalysis. Fertil Steril. 2011;95(3):1048-1058. doi:10.1016/j.fertnstert.2010.11.036

43. Albaghdadi AJ, Feeley CA, Kan FW. Low-dose tacrolimus prevents dysregulated peri-conceptional ovarian and systemic immune cellular homeostasis in subjects with pcos. Sci Rep. 2019;9(1):1-8. doi:10.1038/s41598-019-42960-x

44. Mohammadi S, Bardei LK, Hojati V, Ghorbani A, Nabiuni M. Antiinflammatory effects of curcumin on insulin resistance index, levels of interleukin-6, C-reactive protein, and liver histology in polycystic ovary syndrome-induced rats. Cell J. 2017;19(3):425.

45. Jadhav M, Menon S, Shailajan S. Antiandrogenic effect of Symplocos racemosa Roxb. against letrozole induced polycystic ovary using rat model. J Coast Life Med. 2013;1:309-414.

46. Yakubu MT, Ibiyo BO. Effects of aqueous extract of Cnestis ferruginea (Vahl ex DC) root on the biochemical and clinical parameters of anastrozole-induced polycystic ovarian syndrome rat model. J Endocrinol Reprod. 2013;17:99-112.

47. Tiwari-Pandey R, Ram Sairam M. Modulation of ovarian structure and abdominal obesity in curcumin-and flutamide-treated aging FSH-R haploinsufficient mice. Reprod Sci. 2009;16(6):539-550. doi: $10.1177 / 1933719109332822$

48. Liu L, Bai Y, Song C, et al. The impact of arginine-modified chitosanDNA nanoparticles on the function of macrophages. $J$ Nanoparticle Res. 2010;12(5):1637-1644. doi:10.1007/s11051-009-9722-y

49. Kwon S, Park JH, Chung H, Kwon IC, Jeong SY, Kim IS. Physicochemical characteristics of self- assembled nanoparticles based on glycol chitosan bearing 5 $\beta$-cholanic acid. Langmuir. 2003;19(24):10188-10193. doi:10.1021/la0350608

50. Du YZ, Wang L, Yuan H, Wei XH, Hu FQ. Preparation and characteristics of linoleic acid-grafted chitosan oligosaccharide micelles as a carrier for doxorubicin. Colloids Surf B Biointerfaces. 2009;69 (2):257-263. doi:10.1016/j.colsurfb.2008.11.030

51. Song Z, Feng R, Sun M, et al. Curcumin-loaded PLGA-PEG-PLGA triblock copolymeric micelles: preparation, pharmacokinetics and distribution in vivo. J Colloid Interface Sci. 2011;354(1):116-123. doi:10.1016/j.jcis.2010.10.024

52. Shigemasa Y, Matsuura H, Sashiwa H, Saimoto H. Evaluation of different absorbance ratios from infrared spectroscopy for analyzing the degree of deacetylation in chitin. Int J Biol Macromol. 1996;18 (3):237-242. doi:10.1016/0141-8130(95)01079-3

53. Son YJ, Jang JS, Cho YW, et al. Biodistribution and anti-tumor efficacy of doxorubicin loaded glycol-chitosan nanoaggregates by EPR effect. $J$ Controlled Release. 2003;91(1-2):135-145. doi:10.1016/S0168-3659(03)00231-1 
54. Soppimath KS, Tan DW, Yang YY. pH-triggered thermally responsive polymer core-shell nanoparticles for drug delivery. Adv Mater. 2005;17(3):318-323.

55. Yinsong W, Lingrong L, Jian W, Zhang Q. Preparation and characterization of self-aggregated nanoparticles of cholesterol-modified O-carboxymethyl chitosan conjugates. Carbohydr Polym. 2007;69 (3):597-606.

56. Lai H, Jia X, Yu Q, et al. High-fat diet induces significant metabolic disorders in a mouse model of polycystic ovary syndrome. Biol Reprod. 2014;91(5):127. doi:10.1095/biolreprod.114.120063

57. Brawer JR, Munoz M, Farookhi R. Development of the polycystic ovarian condition (PCO) in the estradiol valerate-treated rat. Biol Reprod. 1986;35(3):647-655. doi:10.1095/biolreprod35.3.647

58. Caldwell AS, Middleton LJ, Jimenez M, et al. Characterization of reproductive, metabolic, and endocrine features of polycystic ovary syndrome in female hyperandrogenic mouse models. Endocrinology. 2014;155:3146-3159. doi:10.1210/en.2014-1196

59. Jitendra PA, Pravin TA. Prospective use of Tephrosia purpurea in remedial treatment of PCOS: study in Wistar rat. ISCA J Biol Sci. 2012;1:1-6.

60. Salvetti NR, Canal AM, Gimeno EJ, Ortega HH. Polycystic ovarian syndrome: temporal characterization of the induction and reversion process in an experimental model. Brazilian J Veter Res Animal Sci. 2004;41(6):389-395. doi:10.1590/S1413-95962004000600006

61. Magny IB, Iliopolous R, Zana R, Audebert R. Mixed micelles formed by cationic surfactants and anionic hydrophobically modified polyelectrolytes. Langmuir. 1994;10:3180-3187. doi:10.1021/ la00021a047

62. Soppimath KS, Tan DW, Yang YY. pH-triggered thermally responsive polymer core-shell nanoparticles for drug delivery. Adv Mater. 2005;17(3):318-323. doi:10.1002/adma.200401057

63. Yinsong W, Lingrong L, Jian W, Zhang Q. Preparation and characterization of self-aggregated nanoparticles of cholesterol-modified O-carboxymethyl chitosan conjugates. Carbohydr Polym. 2007;69 (3):597-606. doi:10.1016/j.carbpol.2007.01.016

64. Liu KH, Chen SY, Liu DM, Liu TY. Self-assembled hollow nanocapsule from amphiphatic Carboxymethyl-hexanoyl chitosan as drug carrier. Macromolecules. 2008;41(17):6511-6516. doi:10.1021/ma8002399

65. Kim K, Kwon S, Park JH, et al. Physicochemical characterizations of selfassembled nanoparticles of glycol Chitosan-Deoxycholic acid conjugates. Biomacromolecules. 2005;6(2):1154-1158. doi:10.1021/bm049305m

66. Arias JL, Gallardo V, Gómez-Lopera SA, Plaza RC, Delgado AV. Synthesis and characterization of poly (ethyl-2-cyanoacrylate) nanoparticles with a magnetic core. $J$ Control Release. 2001;77 (3):309-321. doi:10.1016/S0168-3659(01)00519-3

67. Maeda H, Wu J, Sawa T, Matsumura Y, Hori K. Tumor vascular permeability and the EPR effect in macromolecular therapeutics: a review. J Control Release. 2000;65(1-2):271-284. doi:10.1016/ S0168-3659(99)00248-5

International Journal of Nanomedicine

\section{Publish your work in this journal}

The International Journal of Nanomedicine is an international, peerreviewed journal focusing on the application of nanotechnology in diagnostics, therapeutics, and drug delivery systems throughout the biomedical field. This journal is indexed on PubMed Central, MedLine, CAS, SciSearch ${ }^{\circledR}$, Current Contents ${ }^{\circledR} /$ Clinical Medicine,
68. Monsky WL, Fukumura D, Gohongi T, et al. Augmentation of transvascular transport of macromolecules and nanoparticles in tumors using vascular endothelial growth factor. Cancer Res. 1999;59(16):4129-4135.

69. Liu J, Lihua L, Chuantong L, et al. Preparation and characterization of curcumin nanoparticles for improvement of cellular uptake. Carbohydr Polym. 2012;90:16-22. doi:10.1016/j.carbpol.2012.04.036

70. Muller RH, Mader K, Gohla S. Solid lipid nanoparticles (SLN) for controlled drug delivery-a review of the state of the art. Eur J Pharm Biopharm. 2000;50:161-177. doi:10.1016/S0939-6411(00)00087-4

71. Ravindran J, Prasad S, Aggarwal BB. Curcumin and cancer cells: how many ways can curry kill tumor cells selectively? AAPS J. 2009;11(3):495-510.

72. Fonseca SB, Pereira MP, Kelley SO. Recent advances in the use of cell-penetrating peptides for medical and biological applications. $A d v$ Drug Deliv Rev. 2009;61(11):953-964. doi:10.1016/j.addr.20 09.06.001

73. Fischer R, Fotin-Mieczek M, Hufnagel H, Brock R. Break on through to the other side-biophysics and cell biology shed light on cell-penetrating peptides. Chembiochem. 2005;6(12):2126-2142. doi: $10.1002 /$ cbic. 200500044

74. Nagahara H, Vocero-Akbani AM, Snyder EL, et al. Transduction of full-length TAT fusion proteins into mammalian cells: TAT-p27Kip1 induces cell migration. Nat Med. 1998;4:1449-1452. doi:10.1038/ 4042

75. Mohanty C, Sahoo SK. The in vitro stability and in vivo pharmacokinetics of curcumin prepared as an aqueous nanoparticulate formulation. Biomaterials. 2010;31(25):6597-6611. doi:10.1016/j. biomaterials.2010.04.062

76. Gong CY, Deng SY, Wu QJ, et al. Improving antiangiogenesis and anti-tumor activity of curcumin by biodegradable polymeric micelles. Biomaterials. 2013;34(4):1413-1432. doi:10.1016/j.biomaterials.20 12.10.068

77. Li S, Zhai J, Liu J, et al. Erythropoietin-producing hepatocellular A7 triggering ovulation indicates a potential beneficial role for polycystic ovary syndrome. EBioMedicine. 2018;36:539-552. doi:10.1016/j. ebiom.2018.09.046

78. Wang $\mathrm{M}$, Zhao $\mathrm{D}, \mathrm{Xu} \mathrm{L}$, et al. Role of PCSK9 in lipid metabolic disorders and ovarian dysfunction in polycystic ovary syndrome. Metabolism. 2019;94:47-58. doi:10.1016/j.metabol.20 19.02.002

79. Zhang S, Tu H, Zhu J, et al. Dendrobium nobile Lindl. polysaccharides improve follicular development in PCOS rats. Int $\mathrm{J}$ Biol Macromol. 2020;149:826-834. doi:10.1016/j.ijbiomac.2020.01.196
Journal Citation Reports/Science Edition, EMBase, Scopus and the Elsevier Bibliographic databases. The manuscript management system is completely online and includes a very quick and fair peer-review system, which is all easy to use. Visit http://www.dovepress.com/ testimonials.php to read real quotes from published authors. 